\title{
Transgenic Poplar Plants for the Investigation of ABA-Dependent Salt and Drought Stress Adaptation in Trees
}

\author{
Domenica Hamisch ${ }^{1}$, David Kaufholdt' ${ }^{1}$ Jennifer-Christin Kuchernig', Florian Bittner ${ }^{1}$, \\ Ralf R. Mendel' ${ }^{1}$ Robert Hänsch ${ }^{*}$, Jennifer Popko ${ }^{2}$ \\ ${ }^{1}$ Institut für Pflanzenbiologie, Technische Universität Braunschweig, Braunschweig, Germany \\ ${ }^{2}$ Albrecht-von-Haller-Institutfür Pflanzenwissenschaften, Abteilung Biochemie der Pflanzen, \\ Georg-August-Universität, Göttingen, Germany \\ Email: *r.haensch@tu-bs.de
}

Received 4 March 2016; accepted 15 July 2016; published 18 July 2016

Copyright (C) 2016 by authors and Scientific Research Publishing Inc.

This work is licensed under the Creative Commons Attribution International License (CC BY). http://creativecommons.org/licenses/by/4.0/

(c) (i) Open Access

\section{Abstract}

Important functions of the plant hormone abscisic acid (ABA) in stress reactions, growth and photosynthetic processes are extensively studied in the model plant Arabidopsis thaliana. This paper investigates the importance of Moco-sulphurase ABA3 and aldehyde oxidase (AO) on ABAbiosynthesis in Populus $\times$ canescens. ABA3 is essential for activation of the molybdenum enzymes $\mathrm{AO}$ and xanthine dehydrogenase (XDH). AO itself catalyzes the last step in ABA-biosynthesis. Generation of transgenic poplar plants altered in ABA3 and AO-activity using RNAi knock down and overexpression was performed. Whereas RNAi-AO plants show a specific loss of AO activity, the RNAi-ABA3 plants has a strongly reduced activity of both molybdenum enzymes: AO and XDH. Constructs of $\mathrm{AO}$ and $\mathrm{ABA} 3$-promoters fused to $\beta$-glucuronidase provide the basis to investigate transcriptional regulation of ABA-biosynthetic processes under stress conditions. Application of high salt concentrations and different drought stress intensities does change the endogenous AO or XDH neither on the side of transcription nor on protein activity. On phytohormone level however, water loss leads to increased ABA-amounts regardless of whether transgenic or wildtype plants are studied. Salt application resulted in higher ABA-levels in all analyzed plant lines. The down regulation of $\mathrm{AO}$ in the two different RNAi-plant lines strongly prevented a wildtype-like increase of ABA-levels. Whereas the WT plants accumulated up to $6000 \mathrm{ng} \mathrm{ABA}^{-1} \mathrm{FW}^{-1}$ after $16 \mathrm{~h}^{\text {of }}$ salt stress exposure, plants of the RNAi lines revealed a markedly lower increase of only up to 2000 ng ABA g-1 $\mathrm{FW}^{-1}$. Opposing to these observations, ABA-levels increased during drought without any influence by the RNAi-effect. These results revealed that although stresses did not result in a visible increased AO-activity, ABA-production was influenced by $\mathrm{AO}$ and $\mathrm{ABA} 3$ at least under salinity.

\footnotetext{
${ }^{*}$ Corresponding author.
}

How to cite this paper: Hamisch, D., Kaufholdt, D., Kuchernig, J.-C., Bittner, F., Mendel, R.R., Hänsch, R. and Popko, J. (2016) Transgenic Poplar Plants for the Investigation of ABA-Dependent Salt and Drought Stress Adaptation in Trees. American Journal of Plant Sciences, 7, 1337-1356. http://dx.doi.org/10.4236/ajps.2016.79128 
Keywords

ABA Biosynthesis, Drought Stress, Populus $\times$ canescens, Transgenic Poplar, Salt Stress

\section{Introduction}

Every organism depends to some extend on water supply. Plant cell expansion and vegetative growth are heavily dependent upon a positive water-generated turgor pressure which is maintained by keeping a constant osmotic potential. Abiotic factors such as high salinity and drought cause shifts in this osmotic potential. To overcome those stresses and to avoid disorders in plant cell activities or even plant death, different defense mechanisms have evolved.

Water deficits in plant cells result in ionic, osmotic or mechanical signals, which are all differentially recorded by several receptors. Since these signals have an influence on plant cell turgor they lead to conformational changes of membrane proteins and activate further signaling cascades [1]. Multiple primary receptors initiate secondary signals like hormones and secondary messengers, whereby the plant hormone abscisic acid (ABA) is participating in stress responses. ABA has broad functions in growth and development but it is mainly involved in plant water status regulation [1]-[4]. Maintenance of water status is mediated by ABA-induced $\mathrm{H}_{2} \mathrm{O}_{2}$ production, which further leads to stomatal closure by changing $\mathrm{Ca}^{2+}$ channels in guard cells [1]. ABA is further needed to induce the transcription of dehydration tolerance genes [4]-[6]. These signals and reactions are extended in secondary responses by triggering the already generated signals to gain maximal efficiency. Although both salinity and drought lead to ABA release, a further upstream component involved in salinity response makes these stresses distinguishable: the SOS pathway (Salt Overly Sensitive, [4]). This results in activation of membrane associated $\mathrm{Na}^{+} / \mathrm{H}^{+}$antiporters, which are directly involved in recovering ion homeostasis [1] [4] [7] [8].

ABA synthesis is compartmentalized and starts within the plastids: associated genes were identified initially in ABA-deficient Arabidopsis mutants [2] [9]-[15]. In Arabidopsis, ABA synthesis starts with the cleavage of a $\mathrm{C}_{40}$ carotenoid precursor, which is further epoxidized to violaxanthin by zeaxanthinepoxidase (ZEP). NCED3 (9'-cis-epoxycarotenoid dioxygenase 3) generates xanthoxin by cleavage of 9-cis violaxanthin and 9-cis neoxanthin. After transporting xanthoxin across the plastid membranes, ABA is formed via abscisic aldehyde in the cytoplasm. This involves two enzymatic steps catalyzed by the short-chain dehydrogenase ABA2 and the AAO3 protein [2] [12] [16] [17]. NCED3 and AAO3 catalyze the two known key regulatory steps of ABA biosynthesis in Arabidopsis [2] [18] [19].

Climatic changes in general affect plant growth, susceptibility to abiotic stresses such as drought and salinity and, in this regard, food and wood producing economies. Therefore, research especially on tree stress reaction mechanisms is necessary to obtain instruments overcoming those changes. Poplar plants are widely spread to function in timber production, for bioenergy generation and are also used in environmental protection [20]-[22]. Furthermore, various Populus species serve as models for woody plants [20] [23]-[26] and sequencing of the Populus trichocarpa genome [27] offers the possibility to study ABA biosynthesis. Based on the identified sequences it is assumed that ABA formation in trees follows the biosynthetic pathway known from Arabidopsis [20]. Yet, the regulation of ABA metabolism, long/short distance translocation and the control steps in ABA biosynthesis are still not fully understood neither in Arabidopsis nor in Populus. We therefore intend to shed more light on the regulation of ABA synthesis by studying the roles of aldehyde oxidase (AO) and its regulator enzyme ABA3. AO belongs to the five molybdenum enzymes known in plants [28] [29] and its activity requires complexation with a sulphurated molybdenum cofactor (Moco). In Arabidopsis this final activation step is catalyzed by the Moco sulphurase ABA3 [30]-[33], which responds to the same stimuli like its target enzyme AO including drought, salt, cold and freezing stress, but also to endogenously and exogenously applied ABA [6] [30] [32]. Furthermore, overexpression of ABA3 in cotton and tobacco resulted in enhanced stress tolerance by increased ABA levels, thereby supporting a crucial function for this regulatory protein in ABA biosynthesis [34] [35].

In our investigations we used Populus $\times$ canescens with modulations in AO and ABA3 activity generated via Rhizobium mediated stable poplar transformation. Because poplar gene knockouts are difficult to generate due to long generation times we used RNAi-constructs [36] for decreasing AO enzyme activity and consequently, decreasing endogenous ABA levels. For $a b a 3$ and $a o$ promoter analyses, $\beta$-glucuronidase (GUS) fusion approaches were used. ABA levels and AO activities were determined to uncover similarities or differences in ABA 
modulating mechanisms across the species Populus and Arabidopsis to get deeper insights into poplar ABA responses during drought and high salinity.

\section{Materials and Methods}

\subsection{Promoter: GUS Constructs}

For analysis of ABA3 transcriptional regulation $1.0 \mathrm{~kb}$ upstream of the PtABA3 coding sequence was amplified from Populus trichocarpa genomic DNA (Primer: Table S1) and the resulting putative ptaba3 promoter sequence was cloned into pRT99GUS [37] using restriction enzymes SmaI and EcoRI. Subsequently, the cassette consisting of the $a b a 3$ promotor, the $\beta$-glucuronidase (GUS) coding sequence was transferred into the binary vector pBIN19 [38] using HindIII restriction sites at the 5' end of the ptaba3 promotor and the 3' end of the terminator. AO transcriptional changes were analysed accordingly using a $1.5 \mathrm{~kb}$ sequence upstream of ptao 2 that was defined as putative promoter sequence and fused to gusA to generate ptao2::gusA transformants. The ptao2 promoter sequence was amplified via nested PCR using P. trichocarpa genomic DNA (Primer: Table S1). The resulting fragment was cloned into the binary vector pKGWSF7 via GATEWAY technology (Life technologies, Darmstadt, Germany). Correctness of cloning was confirmed by DNA sequence analysis (Eurofins MWG Operon, Ebersberg, Germany).

\subsection{RNAi Constructs}

Generation of constructs for PtAO2 and PtABA3 knock down transformants was accomplished according to [36]. For the ABA3-RNAi constructs two exons of ptaba3 (LG_VII 7136650-7136823 (174 bp) and LG_VII 7137117-7137323 (207 bp)) were combined in a fusion PCR using P. trichocarpa DNA as template. For AO-RNAi constructs a 410 bp fragment of the ptao2 sequence was amplified from $P$. trichocarpa genomic DNA (Primer: Table S1). In each case the resulting fragments were used as sense and antisense fragments and exchanged the gusA fragments in the existing RNAi construct from [36] for creating a ptaba3 or ptao2 RNAi cassette, respectively. After generation of the chimeric gene cassettes cloning into the binary vector pBIN19 was achieved via HindIII restriction sites [38].

\subsection{ABA3 Overexpressing Lines}

A 35S-promoter::gfp::35S-terminator construct was generated by fusion of the enhanced version of the cauliflower 35S-promoter and the coding sequence of the enhanced green fluorescence protein ( $g f p)$. NcoI and BamHI sites were inserted into the 5'- and 3'-regions of the full-length Arabidopsis aba3 cDNA by PCR (Primer: Table S1) to allow ligation of $a b a 3$ into the 35S-promoter::gfp::35S-terminator construct after partial digestion with NcoI and complete digestion with BamHI. Subsequently, the 35S-promotor::gfp-aba3::35S-terminator construct was partially digested with BamHI and completely digested with HindIII, which enabled ligation into in the pBIN19 binary vector [38].

\subsection{Poplar Transformation}

Stable transformations were performed with the P. tremula $\times$ P. alba hybrid $P . \times$ canescens (no. 7171-B4, French National Institute for Agricultural research (INRA), Paris, France). Rhizobium tumefaciens (former known as Agrobacterium tumefaciens, strain C58C1/pMP90) was used for transformation of at least 150 internodes. Regeneration from independent callus lines followed the protocol of [39]. Correct transformation of selected plant lines was validated by PCR using specific primer (Table S2). The entire regeneration and selection procedure of transgenic poplar plants lasted about a year, in which in vitro plants were cultivated on modified Murashige and Skoog Medium [40] with half strength Macro-nutrients and $20 \mathrm{~g} \cdot \mathrm{L}^{-1}$ sucrose (M1/2-medium). Hydroponic culture was grown as described earlier in [41]. For ABA3-RNAi plants reduced or absent AO and $\mathrm{XDH}$ activities were chosen as selection criteria, whereas reduced or absent AO activity with simultaneous maintenance of XDH activity were chosen as criterion for AO-RNAi plants. ABA3 overexpressing transformants (GFP-ABA3) were identified by distinct cytoplasmic fluorescence and immune-detection of GFP-ABA3 proteins. PtAO2::GUS and ABA3::GUS plants were selected based on specific GUS activities. For each experimental set three independent transgenic lines of the AO-RNAi, ABA3-RNAi, PtAO2::GUS, ABA3::GUS and the GFP-ABA3 transformants were used. 


\subsection{Salt Stress Application}

Salt stress experiments were executed using in vitro plants of PtAO2::GUS, PtABA3::GUS, AO-RNAi, ABA3-RNAi, GFP-ABA3 and WT plants. Five plants per pot were grown under sterile conditions on $72 \mathrm{~mL}$ $\mathrm{M} 1 / 2$ medium in the absence of $\mathrm{NaCl}$. After six weeks $3 \mathrm{~mL}$ sterile $\mathrm{NaCl}$ solution were added to the medium to final concentrations of 50,75, 100 and $150 \mathrm{mM}$. Instead of $\mathrm{NaCl}$ water was added to the control plants. After different time points $(1,5,16,24,40$ and $120 \mathrm{~h}$ ) whole plants were harvested and roots were removed. Shoots were frozen in liquid nitrogen for further analyses. Total protein extracts were prepared from one individual of each plant line and used exemplarily for $\mathrm{AO}$ and $\mathrm{XDH}$ activity staining. Two to five plants were used for ABA measurements in replicates of three to nine.

\subsection{Drought Stress Application}

Drought stress experiments were performed with detached leaves of hydroponically grown plants (PtABA3:: GUS, AO-RNAi, ABA3-RNAi, GFP-ABA3) or alternatively with detached leaves of in vitro plants (PtAO2:: GUS). Middle-aged leaves of poplar (height approx. $80 \mathrm{~cm}$ ) were clipped off and dried in a glass Petri dish $(Q$ $15 \mathrm{~cm}$ ) to a remaining fresh weight of $80 \%$ in approx. 8 to $10 \mathrm{~h}$ and to $60 \%$ in approx. 22 to $24 \mathrm{~h}$. The complete number of leaves from in vitro poplar (6 weeks old) was handled in $\varnothing 6 \mathrm{~cm}$ plastic Petri dishes. The drying process was observed hourly at the beginning and shortly before achieving the correct drought stress intensity. Leaf material was harvested and veins removed from hydroponically cultivated poplar after reaching the appropriate drying stage. Total leaves of in vitro grown poplar were harvested after having reached the desired drought stage and leaf samples were frozen in liquid nitrogen. As for salt stress experiments one sample from each transgenic line was used representatively to visualize AO and XDH activities. Two to five plants were used for ABA measurements in replicates of three to six.

\subsection{Protein Extraction}

$150 \mathrm{mg}$ plant material was ground in liquid nitrogen, sonified in $200 \mu \mathrm{L}$ extraction buffer (100 mM potassium phosphate, pH 7.5, $5 \mathrm{mM}$ DTT, $2 \mathrm{mM}$ EDTA) and centrifuged at $4^{\circ} \mathrm{C}$. For GUS measurements $150 \mathrm{mg}$ plant material were homogenized in $500 \mu \mathrm{L}$ of $50 \mathrm{mM}$ potassium dihydrogen orthophosphate and $1 \mathrm{mM}$ DTT using a Precellys tissue homogenizer (6500 rpm, two times for $15 \mathrm{sec}$ including $15 \mathrm{sec}$ pause; Precellys 24, Bertin Technologies, Montigny-le-Bretonneux, France). After disruption plant material was sonicated and centrifuged two times $\left(4^{\circ} \mathrm{C}, 32,000 \mathrm{~g}, 20 \mathrm{~min}\right)$. For $\mathrm{AO}$ and $\mathrm{XDH}$ activity staining the supernatant was mixed with $15 \mathrm{mg}$ polyvinylpyrrolidone (Sigma Aldrich, Steinheim, Germany) and cleared by centrifugation. Protein concentrations were determined according to [42] with bovine serum albumin as a standard.

\subsection{Enzyme Activity Assays (AO, XDH, GUS)}

$\mathrm{AO}$ and XDH activities were determined by in gel activity staining as described in [43] and [44]. Native polyacrylamide gel electrophoresis (7.5\%) was used for separation of $250 \mu$ g protein per sample. Gel staining was applied overnight in $30 \mathrm{~mL}$ staining solution containing $100 \mathrm{mM}$ potassium phosphate, $18 \mathrm{mg}$ methylthiazolyldiphenyl-tetrazolium bromide and $0.25 \mu \mathrm{M}$ phenazinemethosulphate. Indole-3-carboxaldehyde was used for AO activity detection and a mixture of $15 \mathrm{mg}$ xanthine and $15 \mathrm{mg}$ hypoxanthine for detection of XDH activity (substrates purchased by Sigma Aldrich).

GUS activities of AO::GUS and ABA3::GUS transformants were assayed using $50 \mu \mathrm{L}$ protein extract in 450 $\mu \mathrm{L}$ GUS reaction buffer (50 mM potassium phosphate buffer, $\mathrm{pH} 7.0,10 \mathrm{mM} \beta$-mercaptoethanol, $10 \mathrm{mM}$ $\mathrm{Na}_{2}$-EDTA, $0.1 \% \mathrm{~N}$-lauroylsarcosine, $0.1 \%$ triton X-100 and $1 \mathrm{mM}$ 4-methylumbelliferyl-D-glucuronide hydrate) at $37^{\circ} \mathrm{C}$. The reaction was stopped after 10,20 and $30 \mathrm{~min}$ in $0.2 \mathrm{M}$ sodium carbonate and the reaction product 4-methylumbelliferone (4-MU) was measured using a luminescence spectrometer LS30 (Perkin-Elmer, Massachusetts, USA) or the Tristar Multimode Plate Reader (Berthold Technologies, Wildbad, Germany) detecting excitation at $365 \mathrm{~nm}$ and emission at $455 \mathrm{~nm}$. GUS activity was calculated using a 4-MU standard.

\subsection{ABA Determination}

ABA concentrations were determined using the Phytodetek ABA enzyme immunoassay test kit (Agdia Inc., Elkhart, USA) according to the manufacturer's protocol. Aqueous isolation allowed the simultaneous measure- 
ment of physiologically active ABA as well as the inactive form ABA-GE (abscisic acid- $\beta$-D-glucopyranosylester).

\subsection{Immunoblot and Immunodetection}

For immunodetection $50 \mu$ g protein were separated by 7.5\% SDS polyacrylamide gel electrophoresis (SDSPAGE) prior to transfer onto nitrocellulose membrane (Hybond-P, GE Healthcare, Fairfield, USA) by electro-blotting. As protein marker PageRulerTM Prestained Protein Ladder (Fermentas, St. Leon-Rot, Germany) was used. The primary anti GFP-antibody (Anti-GFP rabbit polyclonal serum, Invitrogen, Darmstadt, Germany) was diluted 1:750 prior to use. The detection was finalized with an alkaline phosphatase-conjugated anti-rabbit antibody (Sigma Aldrich), diluted 1:7500 prior to use, and BCIP/NBT staining reagents (Promega, Fitchburg, USA).

\subsection{Microscopic Analyses}

Fluorescence of the lower leaf epidermis was visualized with the confocal laser scanning microscope (cLSM) 510 META (Release Version 4.2 SP1) connected to an Axiovert 200M (Carl Zeiss, Oberkochen, Germany). The specimens were examined either using the C-Apochromat 40x/1.2 water-immersion objective for detailed pictures with excitation using the argon laser (488 nm line for GFP and chlorophyll auto-fluorescence). The emitted light passed the primary beam splitting mirrors UV/488/543/633 and was separated by a secondary beam splitter at $545 \mathrm{~nm}$. Fluorescence was detected with filter sets as follows: BP 505-530 for GFP and LP 650 for red auto-fluorescence of chlorophyll. When appropriate, the bright field images of samples were imaged with the transmitted light photomultiplier, and the Lambda-mode was used to examine the spectral signature of fluorophores. All images were processed with LSM Image Browser Release 4.2 (Carl Zeiss).

\section{Results}

\subsection{Identification of Poplar AO and ABA3}

Arabidopsis thaliana AO genes comprise a multigene family of four isoforms: aao1 (AT5G20960), aao2 (AT3G43600), aao3 (AT2G27150) and aao4 (AT1G04580) [45]. P. trichocarpa shotgun sequence assemblies were annotated, preferentially based on their homologies to A. thaliana genes [27], which established the basis for identification of $P$. trichocarpa genes. NCBI (National Center for Biotechnology Information,

www.ncbi.nlm.nih.gov) recorded four Poplar AO isoforms: ptao1 (GI: 224104955), ptao2 (GI: 224131694), ptao3 (GI: 224145733) and ptao4 (GI: 224145729). ptao1 presents most notable similarities to aao2 and aao4, and ptao 2 presents similarities to aao 1 and aao3. ptao3 and ptao 4 represent truncated sequences (Supporting Information Figure S1) and are thus likely to be derived from incomplete gene duplication events. Therefore, two AO isoforms were expected for P. trichocarpa [18] with PtAO2 being the most likely candidate for representing the ABA-synthesizing protein isoform due its similarity to AAO3.

In Arabidopsis, the Moco sulphurating enzyme ABA3 (At1g16540) regulates the activation of AO and XDH by inserting a sulphur atom into the Moco to generate its sulphurized form, which is required by AO and XDH to accomplish their tasks in drought and salt stress reactions [13] [30]. ptaba3 is described in the P. trichocarpa database (www.phytozome.net) as POPTR_0007s08330/PtABA3 (“similar to ABA DEFICIENT 3") representing an 'ortholog of Arabidopsis At1g16540'. The comparison of the aba3 and the ptaba3 domain structures clearly demonstrates this orthology (Supporting Information Figure S2).

\subsection{Characterization of Poplar Transformants}

Generation of the different transgenic poplar lines was accomplished using a minimum of 150 internodes for each construct, from which 7 to 44 independent callus lines were established. According to the used constructs, 33 to 128 plants were regenerated (Supporting Information Figure S3). Three plant lines from independent original calli were chosen for further analyses. Plant lines for promoter-GUS transformants (PtABA3::GUS and PtAO2::GUS) were selected with regard to similar expression levels of gusA: no. 8, 27 and 50 for PtABA3::GUS and no. 12, 19 and 20 for PtAO2::GUS (Supporting Information Figure S4).

AO- and ABA3-RNAi lines were chosen after PCR verification of the insertion of the RNAi cassette and based on $\mathrm{AO}$ and $\mathrm{XDH}$ activity staining results. Among AO-RNAi transformants, lines with residual AO activi- 
ty but unaffected XDH activity were selected. ABA3-RNAi plants presenting neither AO nor XDH activity were used (Figure 1 \& Figure 2).

Expression of GFP-ABA3 fusion proteins in transgenic lines was detected by immunoblot analyses using a GFP-specific antibody. GFP-ABA3 expressing poplars no. 6, 14b and 28 presented a distinct band in the range of $117 \mathrm{kDa}$ representing the calculated size of the fusion protein (92 kDa ABA3 plus $27 \mathrm{kDa}$ GFP, Figure 3(a)). Confocal laser scanning microscopy of the fusion protein in poplar leaves verified the transformation. Moreover, GFP-specific fluorescence was completely precluded from organelles and gave a clear cytoplasmic localization (Figures 3(b)-(d)). The lambda mode verified the GFP-specific emission at $515 \mathrm{~nm}$ (Figure 3(e)).

The growing behavior of all transgenic poplar lines was studied in in vitro and hydroponic cultures and compared to the appearance of WT plants. Morphological characteristics of the plants (size of the plant, leaf size and shape, stem diameter, guard cell size and guard cell numbers per leaf area) did not differ between the different transgenic plants and the WT. At non-stressed conditions, the ABA content of ABA3-RNAi, AO-RNAi and GFP-ABA3 poplar transformants ranged around basal WT level (Figure 4 \& Figure 5).

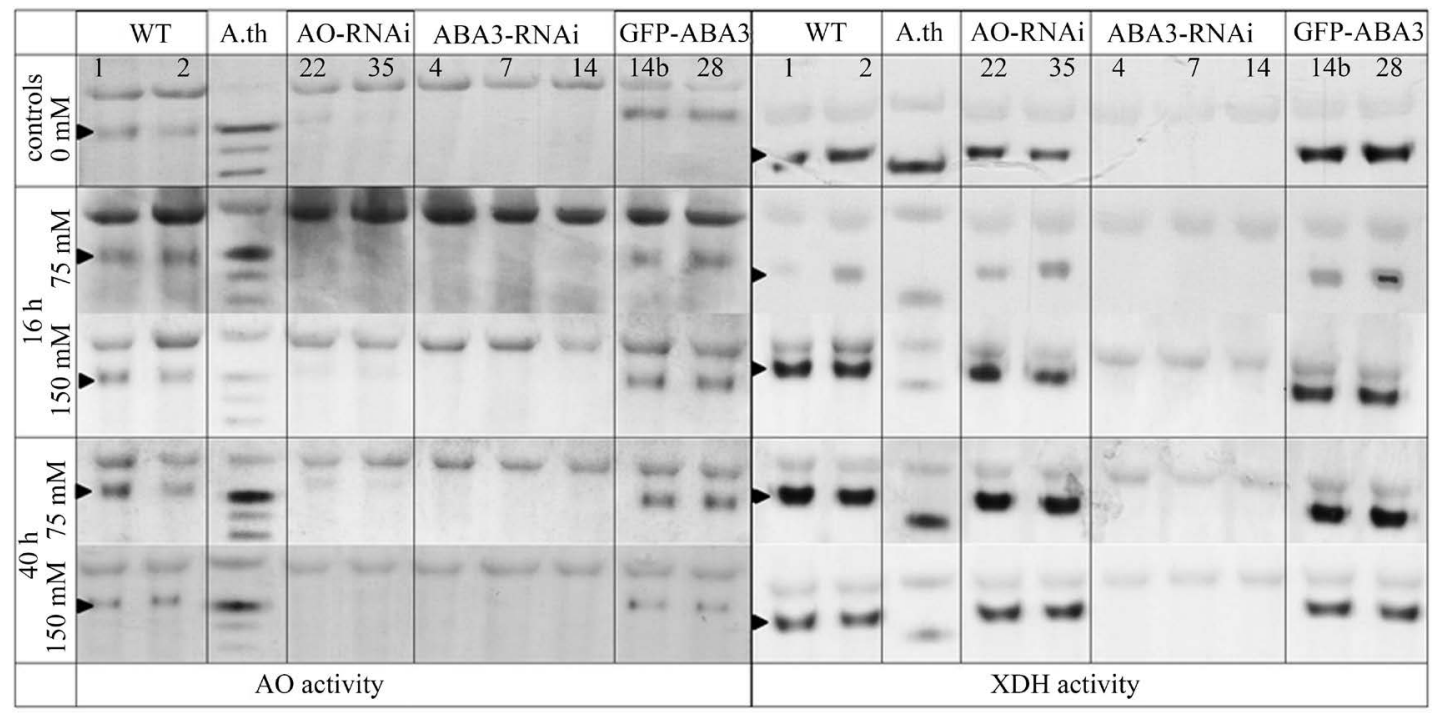

Figure 1. AO and $\mathrm{XDH}$ in gel activity assays of control and transgenic poplar plants after $\mathrm{NaCl}$ stress. Untreated Arabidopsis is shown for comparison. Black arrow-heads mark the respective activity band for AO and XDH. Enzyme activities were determined for poplar wild type (WT) and for plants with a knock down of AO or ABA3 (AO-RNAi no. 22, 35 and ABA3-RNAi no 4, 7, 14) as well as for the ABA3 overexpressing plants (GFP-ABA3, no. 14b and 28). Plants were analyzed at control conditions and after exposure to 75 and $150 \mathrm{mM} \mathrm{NaCl}$ each for 16 and $40 \mathrm{~h}$, respectively.

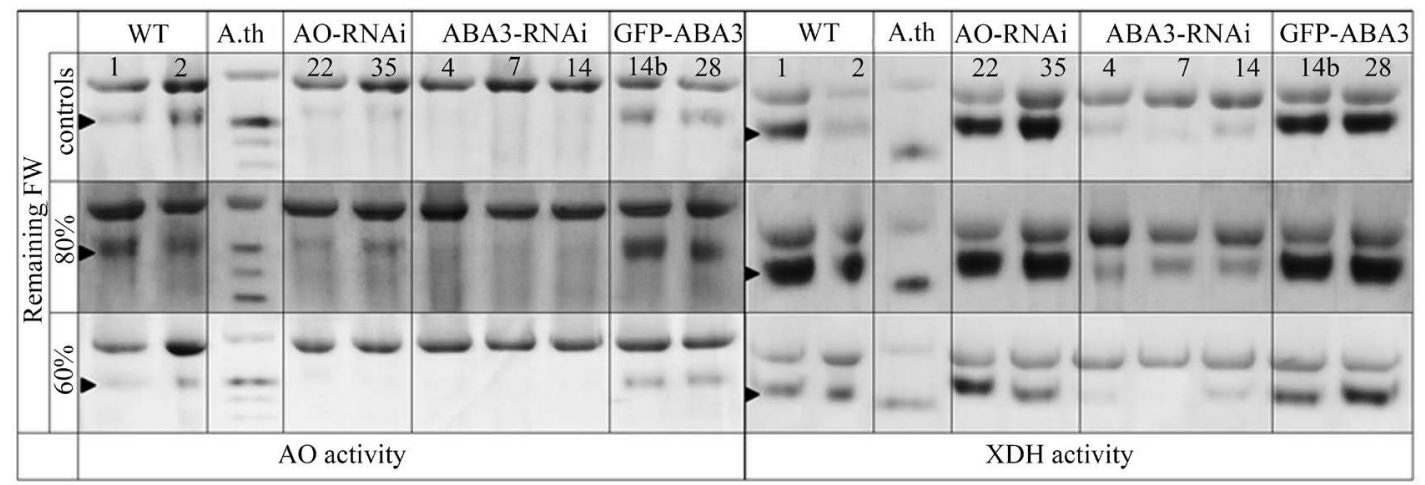

Figure 2. AO and XDH in gel activity assays of control and transgenic poplar plants after drought stress. Untreated Arabidopsis is shown for comparison. Black arrow-heads mark the respective activity band for AO and XDH. Enzyme activities were determined for poplar wild type (WT) and for plants with a knock down of AO or ABA3 (AO-RNAi no. 22, 35 and ABA3-RNAi no 4, 7, 14) as well as for the ABA3 overexpressing plants (GFP-ABA3, no. 14b and 28). Plants were subjected to drought stress by allowing loss of fresh weight to remaining $80 \%$ and $60 \%$ of their initial fresh weight (FW). 

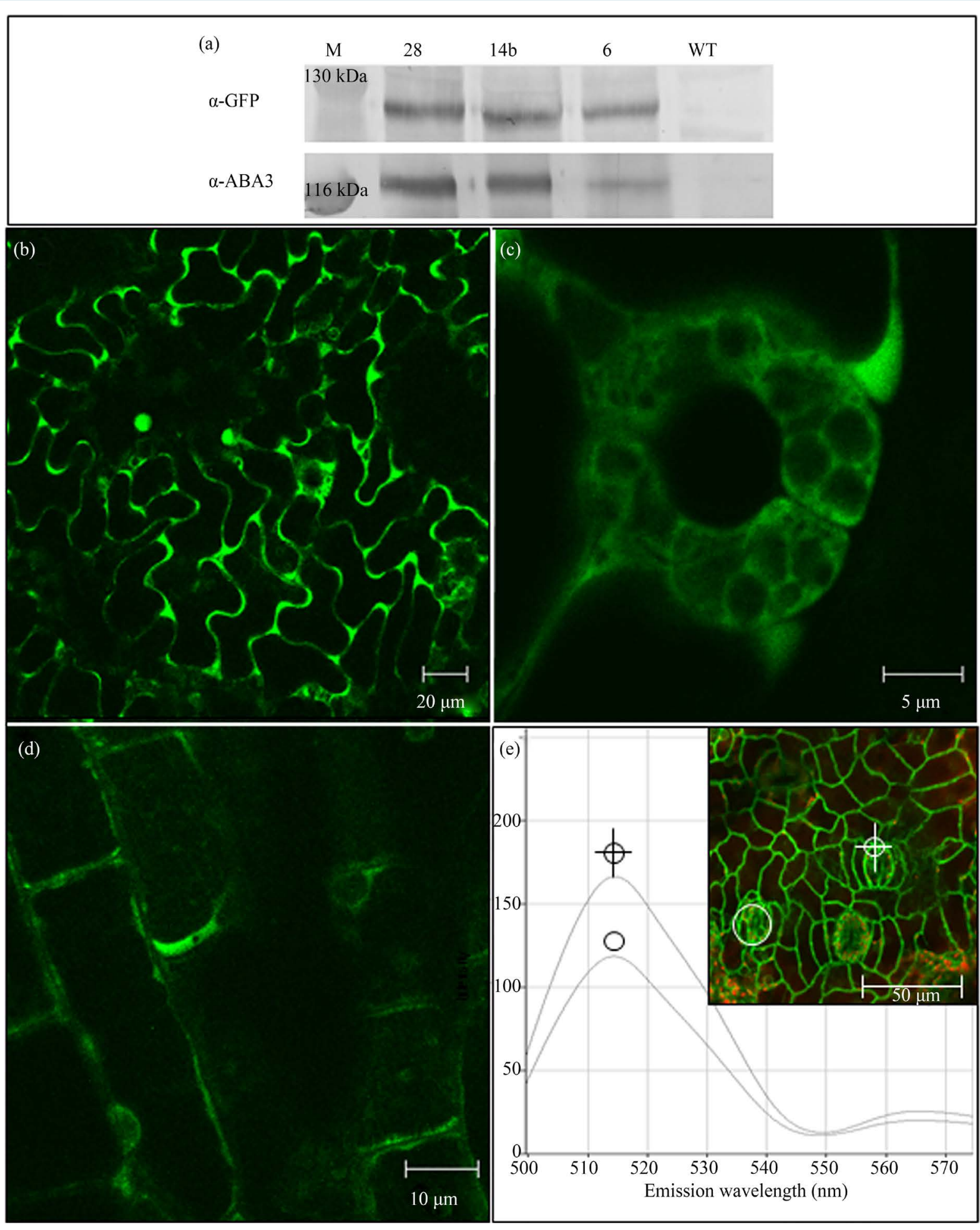

Figure 3. Immunological (a) and microscopic ((b)-(e)) analyses of GFP-ABA3 transformants. (a) The immunological verification of correct poplar transformation was obtained using a green fluorescent protein (GFP)-specific antibody and an antibody against recombinant $A$. thaliana ABA3. Both immuno analyses presented the GFP-ABA3 fragment mass of $117 \mathrm{kDa}$ in all tested poplar lines (no. 28, 14b and 6). No band was detectable in WT plants. Confocal laser scanning microscope (cLSM) analyses presented a clear GFP fluorescence localized in the cytoplasm of GFP-ABA3 plant no. 14b in epidermal cells (b), guard cells (c) and cells of the shoot (d). Lambda mode recordings of the upper epidermis of plant no. 28 resulted in correct GFP-specific emissions at $515 \mathrm{~nm}(\mathrm{e})$. 


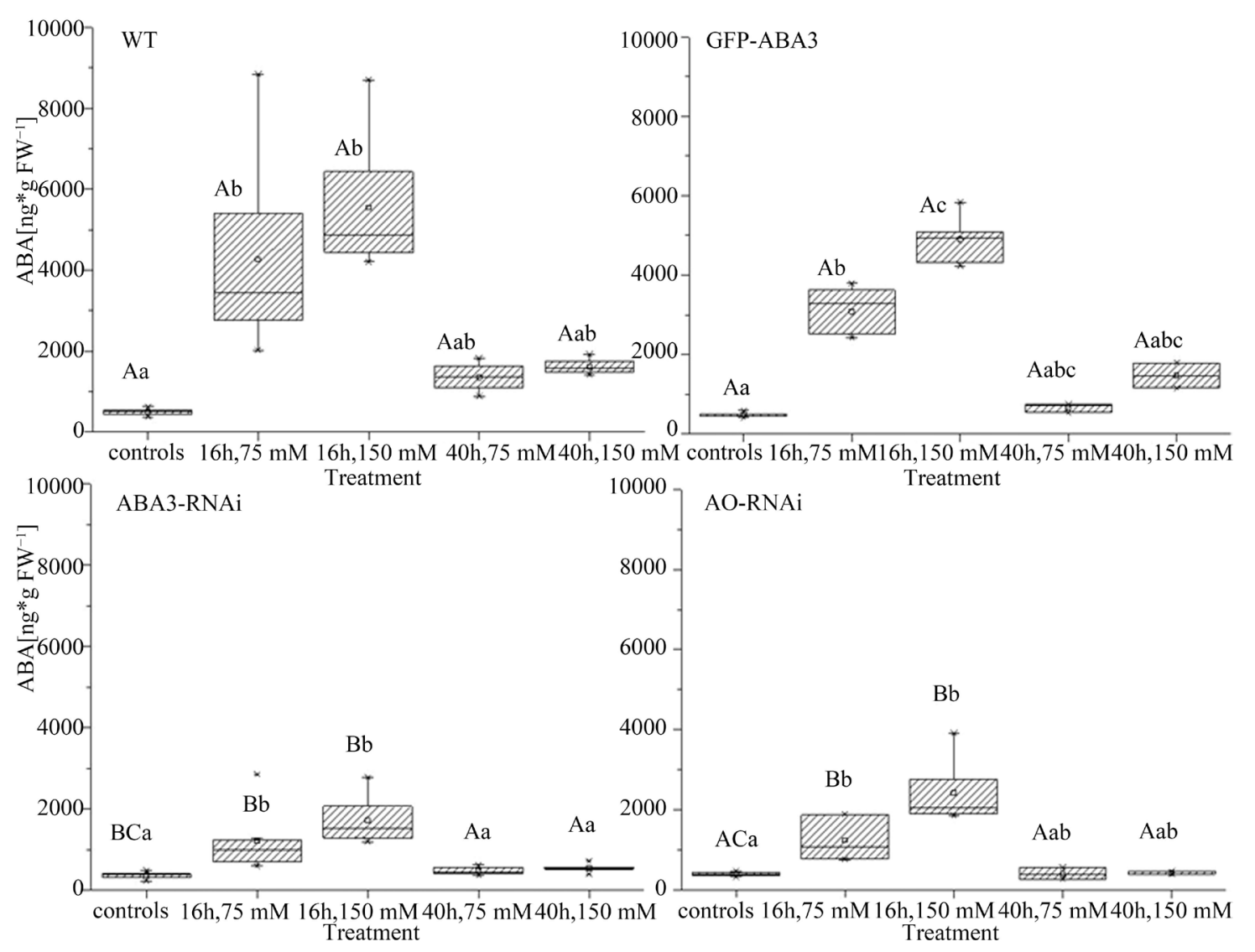

Figure 4. Variation of ABA content in wildtype and transgenic poplar plants after salt stress application. GFP-ABA3 plants (no. 6, 14b and 28) overexpress Arabidopsis ABA3, ABA3-RNAi plants (no. 4, 7, 14) have reduced expression of endogenous Populus aba3 gene and simultaneously strongly decreased AO and XDH activities, AO-RNAi plants (22, 35, 53) showed no AO activity. All plants were treated with 75 and $150 \mathrm{mM} \mathrm{NaCl}$ for 16 and $40 \mathrm{~h}$. Controls without exposure to high salinity were harvested at the beginning of the experiment. ABA content is given in ng ABA per $g$ fresh weight. Significance was calculated using Man-Whitney-U statistics. Small letters indicate changes within the treated lines $(p<0.0025)$ and capital letters describe differences between the different poplar lines $(\mathrm{p}<0.0042)$.

\subsection{ABA3 and AO Transcriptional Regulation}

Promoter-GUS fusion constructs were used to investigate the transcriptional regulation of ptaba3 and ptao2. Therefore, changes in GUS activity of PtAO2::GUS and PtABA3::GUS transformants were analyzed under salt and drought stress conditions. In general, GUS levels of PtAO2::GUS transformants appeared to be three times higher in comparison to ABA3::GUS plants.

When subjected to drought stress conditions at which plants were allowed to lose $20 \%, 40 \%$ and $60 \%$ of fresh weight, GUS activities of ABA3::GUS plants no. 8, 27 and 50 remained stable. For the same plants, 50, 100 and $150 \mathrm{mM} \mathrm{NaCl}$ stress for 1, 5, 24 and 120 h likewise did not alter GUS activities and thus ptaba3 transcription levels (Supporting Information Figure S5). Similar, PtAO2::GUS transformants no. 12, 19 and 20 did not show considerable changes in GUS activity, neither when dehydrated to 80 and $60 \%$ of their respective initial fresh weight, nor when exposed to 75 or $150 \mathrm{mM} \mathrm{NaCl}$ for 16 and $40 \mathrm{~h}$ (Supporting Information Figure S6).

\subsection{ABA Responses to Stress and Modifications in ABA3 and AO Activity}

Leaves of WT and GFP-ABA3 overexpressing plants indeed had the highest AO and XDH activities, while AO and $\mathrm{XDH}$ or only AO activities, respectively, were significantly diminished or not detectable in leaves of ABA3-RNAi and AO-RNAi plants (non-treated material in Figure 1 \& Figure 2).

High salinity for different time intervals in different concentrations generally did not result in phenotypical changes in any of the investigated plant lines. Instead, plants appeared healthy and did not exhibit clear visible 

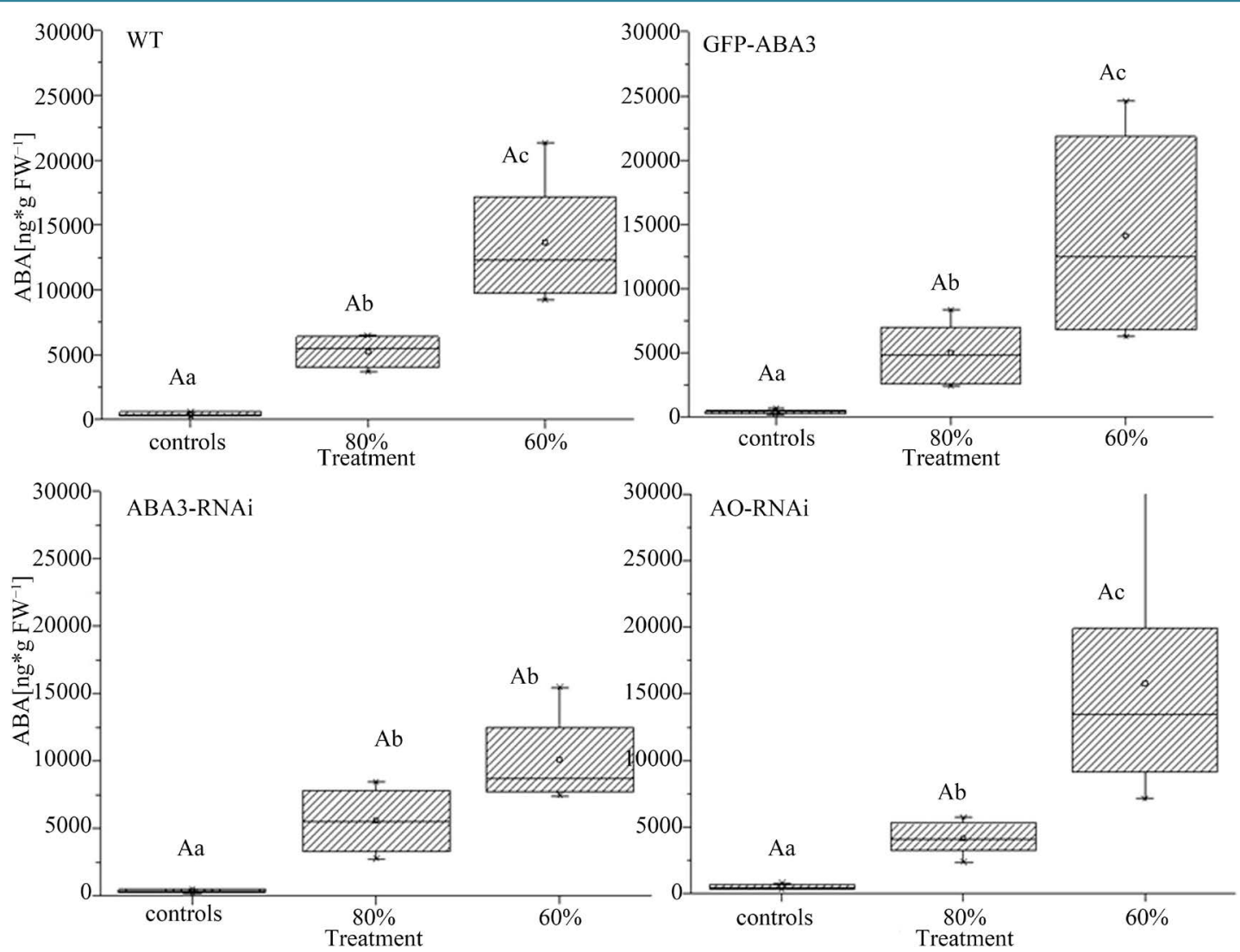

Figure 5. Variation of ABA content in wild type and transgenic poplar plants after drought stress treatment. GFP-ABA3 plants (no. 6, 14b and 28) overexpress Arabidopsis ABA3, ABA3-RNAi plants (no. 4, 7, 14) have reduced expression of endogenous Populus aba3 gene and simultaneously strongly decreased AO and XDH activities, AO-RNAi plants (22, 35, 53) showed no AO activity. All transformants were dried to 80 and $60 \%$ of their initial fresh weight (FW). ABA content of treated and control plants was measured in ng ABA per g fresh weight. In all lines an equally pronounced significant increase of ABA application was observable due to drought stress. Statistics were calculated using ANOVA with post-hoc Holm-Sidak correction. Small letters indicate changes within the treated lines $(\mathrm{p}<0.0001)$ and capital letters describe differences between the different poplar lines $(\mathrm{p}<0.0083)$.

symptoms such as stress-induced senescence. Moreover, no salinity-induced change in AO or XDH enzyme activity was observed in any of the transgenic lines, independent from the salt concentration or the duration of treatment (Figure 1). However, $16 \mathrm{~h}$ after application of $\mathrm{NaCl}$ all plants presented a significant increase in ABA levels at both concentrations 75 and $150 \mathrm{mM}$. Interestingly, this salt stress-induced increase of ABA levels was found to be only transient since ABA levels dropped near to control levels when $\mathrm{NaCl}$ exposure times were extended to $40 \mathrm{~h}$. An important observation in these experiments concerns the total ABA levels in WT and GFP-ABA3 transformants relative to the ABA3- and AO-RNAi lines: while WT and GFP-ABA3 accumulated up to $6000 \mathrm{ng} \mathrm{ABA} \mathrm{g}^{-1} \mathrm{FW}^{-1}$ after $16 \mathrm{~h}$ of salt stress exposure, plants of both RNAi lines revealed a markedly lower increase of only up to $2000 \mathrm{ng} \mathrm{ABA} \mathrm{g}{ }^{-1} \mathrm{FW}^{-1}$ (Figure 4). Although total ABA levels have dropped after $40 \mathrm{~h}$ of salt stress in all plants, the differences between WT and GFP-ABA3 overexpressing plants (about 1000 ng $\mathrm{ABA} \mathrm{g}^{-1} \mathrm{FW}^{-1}$ ) relative to ABA3- and AO-RNAi plants (about $500 \mathrm{ng} \mathrm{ABA} \mathrm{g}^{-1} \mathrm{FW}^{-1}$ ) were still statistically significant, indicating a crucial role of PtAO2 and PtABA3 for salt stress-induced ABA synthesis in poplar.

When subjecting WT, GFP-ABA3, ABA3-RNAi and AO-RNAi leaves to drought stress by allowing them to dehydrate to $80 \%$ and $60 \%$ of their initial fresh weight, all treated leaves clearly appeared flaccid. However, no phenotypical differences were evident between the various transgenics and controls, and also AO and XDH activities remained constant along the drought stress procedure in all investigated poplar leaves (Figure 2). Yet, neither $20 \%$ nor $40 \%$ drought stress-induced loss of fresh weight resulted in markedly altered AO and/or XDH activities relative to untreated leaves. In contrast, ABA levels were strongly enhanced with an overall 5-fold increase after $20 \%$ loss of fresh weight and a 15- to 20 -fold increase after $40 \%$ loss of fresh weight in leaves of all 
plant lines (Figure 5). Unlike salt stress treatment however, drought stress did not expose significantly different response efficiencies between the individual transgenic and control plants, suggesting that the ABA-mediated drought stress response is relatively independent from altered AO and/or XDH activities.

\section{Discussion}

Enzymes involved in Arabidopsis ABA synthesis and signaling have orthologous genes in Populus. The P. trichocarpa genome sequencing project [27] in conjunction with stress experiments involving transgenic plants gave first interesting insights into ABA signaling in poplar [20]. In addition to these previous findings, the present work asks whether the regulation of ABA synthesis under drought and high salinity conditions in Populus is identical to or different from Arabidopsis with a special emphasis on the molybdenum enzymes $\mathrm{AO}$ and $\mathrm{XDH}$ and their common regulator protein ABA3.

In Arabidopsis, AAO3 represents the AO isoform, which catalyzes the oxidation of abscisic aldehyde and which is therefore crucial for ABA synthesis in particular at drought stress conditions [46]. Significant similarities on protein sequences and domain structures between AAO3 and one of the putative poplar AO isogenes lead us to propose that PtAO2 represents the abscisic aldehyde-specific AO isoform in poplar. Such sequence and domain structure similarities also exist between the Arabidopsis Moco sulphurase ABA3 and the putative PtABA3 protein, which therefore served as basis for our investigations in poplar. In this work, the GFP-ABA3 fusion construct allows the characterization of ABA3 as enzyme with clear cytoplasmic localization. 35S::GFPABA3 plants are additionally used for studying the overexpression of the Moco-sulphurase.

GUS expression levels in PtAO2::GUS and PtABA3::GUS plants indicate that basic promoter activities of PtAO2 and PtABA3 are relatively low with the activity of PtAO2 being approximately three times higher than that of PtABA3, which corresponds well to the extremely low gene expression of ABA3 in Arabidopsis [6] [30].

According to their functions in ABA synthesis, Arabidopsis mutants with a deficiency in ABA3 or AAO3 are typically characterized by moderately decreased basal ABA levels but are dramatically impaired in stress-induced ABA synthesis [6] [13] [46] [47]. This indicates a crucial role in ABA synthesis for both AAO3 and ABA3. In fact, some recent work has demonstrated the limitation of ABA synthesis by ABA3 and AAO3 during stomatal closure [48] [49] and natural leaf senescence [50]. On the other hand, overexpression of Arabidopsis ABA3 in heterologous plant species such as cotton [35] and tobacco [34] leads to increased production of ABA and enhances drought stress tolerance, which likewise indicates the limiting nature of ABA3 and its target enzyme AAO3 for ABA synthesis. For trees such as poplar however, genetic modification of the ABA biosynthetic pathway has not been described so far. To shed light on the as yet enigmatic ABA synthesis in poplar we therefore initially studied the transcriptional regulation of PtAO2 and PtABA3, which are likely to resemble the functional orthologues of the two ABA synthesis proteins AAO3 and ABA3 in Arabidopsis, whose expressions are not only induced by abiotic stresses such as drought and salinity but also positively feed-back regulated by ABA [6] [30] [39] [51] [52]. In contrast to Arabidopsis however, the here presented PtAO2::GUS and PtABA3::GUS plants do not display transcriptional regulation of poplar PtAO2 and PtABA3 genes in response to drought or salinity. Nevertheless, a clear accumulation of ABA in response to the applied stresses is detected in all investigated transgenic and control lines, with PtAO2 and PtABA3 obviously having crucial functions in de novo ABA synthesis at salt stress conditions as suggested by less pronounced increases of ABA in PtAO2- and PtABA3-RNAi lines. This clearly indicates that under salt stress conditions de novo synthesis of ABA basically follows similar ways in poplar as compared to Arabidopsis, where both AO and ABA3 catalyze limiting steps in salt stress-induced ABA synthesis.

Another interesting issue concerns the observation that initially increasing ABA levels have dropped to basal levels after $40 \mathrm{~h}$, which however is likewise in agreement with similar situations in other plant species such as Arabidopsis. Osmotic stresses such as salt application and drought are well known to initially stimulate the ABA biosynthetic pathway and the ABA signaling cascade to affect rapid stomatal conductance. The primary aim is to preserve the main plant functions and to simply avoid water loss [18] [20]. Such initial stress responses usually are noticeable in increased ABA content - very similar to what has been demonstrated in this work for all poplar lines after $16 \mathrm{~h}$ of salt stress. Under prolonged stress however, plants attempt to adapt to the present stress conditions by maintaining ABA homeostasis [2] and long-term stress responses - mostly on the gene expression level to further affect photosynthesis, respiration, growth and development [1] [4] [8]. At this point elevated levels of ABA are no longer required and turned back to or near to basal levels, such as those observed 
in poplar $40 \mathrm{~h}$ after salt stress treatment. Obviously and in accordance with herbaceous plant species such as Arabidopsis, short-term salt stress in poplar requires rapid ABA response and thus rapidly increasing ABA concentrations, whereas control conditions and long-term stress are likely to rely on maintenance of ABA homeostasis in first priority [2].

In contrast to salt stress, drought stress caused a similarly high but continuous increase of ABA levels in all investigated poplar lines, independent from the respective genetic manipulation, which is therefore likely to derive from either a remobilization of ABA conjugates or from a de novo synthesis of $\mathrm{ABA}$ in which proteins other than $\mathrm{AO}$ and/or $\mathrm{ABA} 3$ represent limiting factors. Regarding the first hypothesis of $\mathrm{ABA}$ remobilization, Commelina communis maintains a constant total ABA pool consisting of free and conjugated ABA, from which ABA is initially mobilized in response to short-term stress [53]. If this was true also for poplar, no increase of ABA would have been detected upon salt and drought stress treatment as free and conjugated ABA is impossible to be distinguished by the ABA detection method used in this work. Thus, the second hypothesis of stimulated ABA synthesis appears much more likely, albeit AO and ABA3 obviously have no prominent role under drought stress conditions. Yet, de novo ABA synthesis resulting in increased ABA amounts may instead originate from enhanced synthesis of ABA precursors in the chloroplasts such as antheraxanthin, violaxanthin and/or neoxanthin, or from precursors produced in the cytosolic step preceding AO/ABA3-dependent oxidation of abscisic aldehyde to abscisic acid, i.e. from xanthoxin. Since among these possibilities only the production of xanthoxin from 9-cis-violaxanthin and 9-cis-neoxanthin by 9-cis-expoxycarotenoid dioxygenase (in Arabidopsis: NCED3) has been demonstrated to be limiting for ABA synthesis [54]-[56] it can be speculated that this might indeed represent a limiting step also in poplar. Further analysis in this direction will reveal whether this assumption is valid, e.g. by a detailed mRNA expression analysis of ABA synthesis or/and ABA signaling in poplar.

In either case, it can be concluded that poplar appears to have established distinct ways of ABA accumulation for coping with prominent abiotic stresses such as salinity and drought, with its adaptation to salt stress being similar and its adaptation to drought stress being different from the adaptation process in herbaceous plants such as Arabidopsis. PtAO2 and PtABA3 appear to represent enzymes catalyzing critical steps in ABA synthesis under high salt conditions but do not appear to be limiting for ABA synthesis under drought stress conditions. Besides the assumption of distinct ABA responsive ways for salt and drought stress conditions, the possibility must be considered that stress perception, integration and stress response realization in poplar differs from that of herbaceous plants, which however would open other new and interesting fields of research for the next years.

\section{Acknowledgements}

We are grateful to Marion Kay and the students Lisa Deppe, Ulrike Lau and Steffen Bertholdt for excellent technical work in our lab. We thank Dörte Randewig and Cole Meurer for critically reading the manuscript. This work was supported by a grant of the Deutsche Forschungsgemeinschaft (Ha3107/3-3) within the German joint research group "Poplar-A Model to Address Tree-Specific Questions”.

\section{Competing Interests}

The authors have no conflict of interest related to the work described in this manuscript.

\section{References}

[1] Xiong, L. and Zhu, J.K. (2002) Molecular and Genetic Aspects of Plant Responses to Osmotic Stress. Plant, Cell and Environment, 25, 131-139. http://dx.doi.org/10.1046/j.1365-3040.2002.00782.x

[2] Sreenivasulu, N., Harshavardhan, V.T., Govind, G., Seiler, C. and Kohli, A. (2012) Contrapuntal Role of ABA: Does It Mediate Stress Tolerance or Plant Growth Retardation under Long-Term Drought Stress? Gene, 506, 265-273. http://dx.doi.org/10.1016/j.gene.2012.06.076

[3] Umezawa, T., Fujita, M., Fujita, Y., Yamaguchi-Shinozaki, K. and Shinozaki, K. (2006) Engineering Drought Tolerance in Plants: Discovering and Tailoring Genes to Unlock the Future. Current Opinion in Biotechnology, 17, 113-122. http://dx.doi.org/10.1016/j.copbio.2006.02.002

[4] Zhu, J.K. (2002) Salt and Drought Stress Signal Transduction in Plants. Annual Review of Plant Biology, 53, $247-273$. http://dx.doi.org/10.1146/annurev.arplant.53.091401.143329

[5] Llorente, F., Oliveros, J.C., Martinez,-Zapater J.M. and Salinas, J. (2000) A Freezing-Sensitive Mutant of Arabidopsis, frs1, Is a New aba3 Allele. Planta, 211, 648-655. http://dx.doi.org/10.1007/s004250000340 
[6] Xiong, L., Ishitani, M., Lee, H. and Zhu, J.K. (2001) The Arabidopsis LOS5/ABA3 Locus Encodes a Molybdenum Cofactor Sulfurase and Modulates Cold Stress- and Osmotic Stress-Responsive Gene Expression. The Plant Cell, 13, 2063-2083. http://dx.doi.org/10.1105/tpc.13.9.2063

[7] Guo, Y., Halfter, U., Ishitani, M. and Zhu, J.K. (2001) Molecular Characterization of Functional Domains in the Protein Kinase SOS2 That Is Required for Plant Salt Tolerance. The Plant Cell, 13, 1383-1400. http://dx.doi.org/10.1105/tpc.13.6.1383

[8] Xiong, L., Schumaker, K.S. and Zhu, J.K. (2002) Cell Signaling during Cold, Drought, and Salt Stress. The Plant Cell, 14, S165-S183.

[9] Koornneef, M., Jorna, M.L., Brinkhorst-van der Swan, D.L.C. and Karssen, C.M. (1982) The Isolation of Abscisic Acid (ABA) Deficient Mutants by Selection of Induced Revertants in Non-Germinating Gibberellin Sensitive Lines of Arabidopsis thaliana (L.) Heynh. TAG Theoretical and Applied Genetics, 61, 385-393.

[10] Koornneef, M., Léon-Kloosterziel, K.M., Schwartz, S.H. and Zeevaart, J.A.D. (1998) The Genetic and Molecular Dissection of Abscisic Acid Biosynthesis and Signal Transduction in Arabidopsis. Plant Physiology and Biochemistry, 36, 83-89. http://dx.doi.org/10.1016/S0981-9428(98)80093-4

[11] Leon-Kloosterziel, K.M., Gil, M.A., Ruijs, G.J., Jacobsen, S.E., Olszewski, N.E., Schwartz, S.H., Zeevaart, J.A. and Koornneef, M. (1996) Isolation and Characterization of Abscisic Acid-Deficient Arabidopsis Mutants at Two New Loci. The Plant Journal, 10, 655-661. http://dx.doi.org/10.1046/j.1365-313X.1996.10040655.x

[12] Nambara, E. and Marion-Poll, A. (2005) Abscisic Acid Biosynthesis and Catabolism. Annual Review of Plant Biology, 56, 165-185. http://dx.doi.org/10.1146/annurev.arplant.56.032604.144046

[13] Schwartz, S.H., Leon-Kloosterziel, K.M., Koornneef, M. and Zeevaart, J.A. (1997) Biochemical Characterization of the aba2 and aba3 Mutants in Arabidopsis thaliana. Plant Physiology, 114, 161-166. http://dx.doi.org/10.1104/pp.114.1.161

[14] Seo, M. and Koshiba, T. (2002) Complex Regulation of ABA Biosynthesis in Plants. Trends in Plant Science, 7, 41-48. http://dx.doi.org/10.1016/S1360-1385(01)02187-2

[15] Tan, B.C., Schwartz, S.H., Zeevaart, J.A. and McCarty, D.R. (1997) Genetic Control of Abscisic Acid Biosynthesis in Maize. Proceedings of the National Academy of Sciences of the United States of America, 94, 12235-12240. http://dx.doi.org/10.1073/pnas.94.22.12235

[16] Finkelstein, R.R., Gampala, S.S. and Rock, C.D. (2002) Abscisic Acid Signaling in Seeds and Seedlings. The Plant Cell, 14, 15-45.

[17] Finkelstein, R.R. and Rock, C.D. (2002) Abscisic Acid Biosynthesis and Response. The Arabidopsis book / American Society of Plant Biologists, 1, e0058. http://dx.doi.org/10.1199/tab.0058

[18] Popko, J., Hänsch, R., Mendel, R.R., Polle, A. and Teichmann, T. (2010) The Role of Abscisic Acid and Auxin in the Response of Poplar to Abiotic Stress. Plant Biology, 12, 242-258. http://dx.doi.org/10.1111/j.1438-8677.2009.00305.x

[19] Seo, M. and Koshiba, T. (2011) Transport of ABA from the Site of Biosynthesis to the Site of Action. Journal of Plant Research, 124, 501-507. http://dx.doi.org/10.1007/s10265-011-0411-4

[20] Chen, S. and Polle, A. (2010) Salinity Tolerance of Populus. Plant Biology, 12, 317-333. http://dx.doi.org/10.1111/j.1438-8677.2009.00301.x

[21] Luo, Z.-B. and Polle, A. (2009) Wood Composition and Energy Content in a Poplar Short Rotation Plantation on Fertilized Agricultural Land in a Future $\mathrm{CO}_{2}$ Atmosphere. Global Change Biology, 15, 38-47. http://dx.doi.org/10.1111/j.1365-2486.2008.01768.x

[22] Peuke, A. and Rennenberg, H. (2006) Heavy Metal Resistance and Phytoremediation with Transgenic Trees. In: Fladung, M. and Ewald, D., Eds., Tree Transgenesis, Springer, Berlin, 137-155. http://dx.doi.org/10.1007/3-540-32199-3_7

[23] Bradshaw, H.D., Ceulemans, R., Davis, J. and Stettler, R. (2000) Emerging Model Systems in Plant Biology: Poplar (Populus) as a Model Forest Tree. Journal of Plant Growth Regulation, 19, 306-313. http://dx.doi.org/10.1007/s003440000030

[24] Chaffey, N., Barlow, P. and Sundberg, B. (2002) Understanding the Role of the Cytoskeleton in Wood Formation in Angiosperm Trees: Hybrid Aspen (Populus tremula $\times$ Populus tremuloides) as the Model Species. Tree Physiology, 22, 239-249. http://dx.doi.org/10.1093/treephys/22.4.239

[25] Jansson, S. and Douglas, C.J. (2007) Populus: A Model System for Plant Biology. Annual Review of Plant Bbiology, 58, 435-458. http://dx.doi.org/10.1146/annurev.arplant.58.032806.103956

[26] Taylor, G. (2002) Populus: Arabidopsis for Forestry. Do We Need a Model Tree? Annals of Botany, 90, 681-689. http://dx.doi.org/10.1093/aob/mcf255

[27] Tuskan, G.A., Difazio, S., Jansson, S., Bohlmann, J., Grigoriev, I., Hellsten, U., Putnam, N., Ralph, S., Rombauts, S., 
Salamov, A., Schein, J., Sterck, L., Aerts, A., Bhalerao, R.R., Bhalerao, R.P., Blaudez, D., Boerjan, W., Brun, A., Brunner, A., Busov, V., Campbell, M., Carlson, J., Chalot, M., Chapman, J., Chen, G.L., Cooper, D., Coutinho, P.M., Couturier, J., Covert, S., Cronk, Q., Cunningham, R., Davis, J., Degroeve, S., Dejardin, A., Depamphilis, C., Detter, J., Dirks, B., Dubchak, I., Duplessis, S., Ehlting, J., Ellis, B., Gendler, K., Goodstein, D., Gribskov, M., Grimwood, J., Groover, A., Gunter, L., Hamberger, B., Heinze, B., Helariutta, Y., Henrissat, B., Holligan, D., Holt, R., Huang, W., Islam-Faridi, N., Jones, S., Jones-Rhoades, M., Jorgensen, R., Joshi, C., Kangasjarvi, J., Karlsson, J., Kelleher, C., Kirkpatrick, R., Kirst, M., Kohler, A., Kalluri, U., Larimer, F., Leebens-Mack, J., Leple, J.C., Locascio, P., Lou, Y., Lucas, S., Martin, F., Montanini, B., Napoli, C., Nelson, D.R., Nelson, C., Nieminen, K., Nilsson, O., Pereda, V., Peter, G., Philippe, R., Pilate, G., Poliakov, A., Razumovskaya, J., Richardson, P., Rinaldi, C., Ritland, K., Rouze, P., Ryaboy, D., Schmutz, J., Schrader, J., Segerman, B., Shin, H., Siddiqui, A., Sterky, F., Terry, A., Tsai, C.J., Uberbacher, E. and Unneberg, P. (2006) The Genome of Black Cottonwood, Populus trichocarpa (Torr, Gray). Science, 313, $1596-1604$. http://dx.doi.org/10.1126/science.1128691

[28] Mendel, R.R. and Kruse, T. (2012) Cell Biology of Molybdenum in Plants and Humans. Biochimica et Biophysica Acta, 1823, 1568-1579. http://dx.doi.org/10.1016/j.bbamcr.2012.02.007

[29] Mendel, R.R. and Schwarz, G. (2006) Molybdenum Cofactor Biosynthesis and Molybdenum Enzymes. Annual Review of Plant Biology, 57, 623-647. http://dx.doi.org/10.1146/annurev.arplant.57.032905.105437

[30] Bittner, F., Oreb, M. and Mendel, R.R. (2001) ABA3 Is a Molybdenum Cofactor Sulfurase Required for Activation of Aldehyde Oxidase and Xanthine Dehydrogenase in Arabidopsis thaliana. Journal of Biological Chemistry, 276, 40381-40384. http://dx.doi.org/10.1074/jbc.C100472200

[31] Mendel, R.R. and Bittner, F. (2006) Cell Biology of Molybdenum. Biochimica et Biophysica Acta, 1763, 621-635. http://dx.doi.org/10.1016/j.bbamcr.2006.03.013

[32] Sagi, M., Scazzocchio, C. and Fluhr R. (2002) The Absence of Molybdenum Cofactor Sulfuration Is the Primary Cause of the Flacca Phenotype in Tomato Plants. The Plant Journal, 31, 305-317. http://dx.doi.org/10.1046/j.1365-313X.2002.01363.x

[33] Wollers, S., Heidenreich, T., Zarepour, M., Zachmann, D., Kraft, C., Zhao, Y., Mendel, R.R. and Bittner, F. (2008) Binding of Sulfurated Molybdenum Cofactor to the C-Terminal Domain of ABA3 from Arabidopsis thaliana Provides Insight into the Mechanism of Molybdenum Cofactor Sulfuration. Journal of Biological Chemistry, 283, 9642-9650. http://dx.doi.org/10.1074/jbc.M708549200

[34] Yue, Y., Zhang, M., Zhang, J., Duan, L. and Li, Z. (2011) Arabidopsis LOS5/ABA3 Overexpression in Transgenic Tobacco (Nicotiana tabacum cv. Xanthi-nc) Results in Enhanced Drought Tolerance. Plant Science, 181, 405-411. http://dx.doi.org/10.1016/j.plantsci.2011.06.010

[35] Yue, Y., Zhang, M., Zhang, J., Tian, X., Duan, L. and Li, Z. (2012) Overexpression of the AtLOS5 Gene Increased Abscisic Acid Level and Drought Tolerance in Transgenic Cotton. Journal of Experimental Botany, 63, 3741-3748. http://dx.doi.org/10.1093/jxb/ers069

[36] Meyer, S., Nowak, K., Sharma, V.K., Schulze, J., Mendel, R.R. and Hänsch, R. (2004) Vectors for RNAi Technology in Poplar. Plant Biology, 6, 100-103. http://dx.doi.org/10.1055/s-2004-815729

[37] Toepfer, R., Matzeit, V., Gronenborn, B., Schell, J. and Steinbiss, H.H. (1987) A Set of Plant Expression Vectors for Transcriptional and Translational Fusions. Nucleic Acids Research, 15, 5890. http://dx.doi.org/10.1093/nar/15.14.5890

[38] Bevan, M. (1984) Binary Agrobacterium Vectors for Plant Transformation. Nucleic Acids Research, 12, 8711-8721. http://dx.doi.org/10.1093/nar/12.22.8711

[39] Leple, J.C., Brasileiro, A.C., Michel, M.F., Delmotte, F. and Jouanin, L. (1992) Transgenic Poplars: Expression of Chimeric Genes Using Four Different Constructs. Plant Cell Reports, 11, 137-141. http://dx.doi.org/10.1007/BF00232166

[40] Murashige, T. and Skoog, F. (1962) Revised Medium for Rapid Growth and Bio Assays with Tobacco Tissue Cultures. Physiologia Plantarum, 15, 1399-3054. http://dx.doi.org/10.1111/j.1399-3054.1962.tb08052.x

[41] Hänsch, R., Kurz, T., Schulze, J., Mendel, R.R., Cerff, R. and Hehl, R. (2003) Anaerobic Induction of the Maize GapC4 Promoter in Poplar Leaves Requires Light and High $\mathrm{CO}_{2}$. Planta, 218, 79-86. http://dx.doi.org/10.1007/s00425-003-1074-8

[42] Bradford, M.M. (1976) A Rapid and Sensitive Method for the Quantitation of Microgram Quantities of Protein Utilizing the Principle of Protein-Dye Binding. Analytical Biochemistry, 72, 248-254. http://dx.doi.org/10.1016/0003-2697(76)90527-3

[43] Hesberg, C., Hänsch, R., Mendel, R.R. and Bittner, F. (2004) Tandem Orientation of Duplicated Xanthine Dehydrogenase Genes from Arabidopsis thaliana: Differential Gene Expression and Enzyme Activities. The Journal of Biological Chemistry, 279, 13547-13554. http://dx.doi.org/10.1074/jbc.M312929200

[44] Koshiba, T., Saito, E., Ono, N., Yamamoto, N. and Sato, M. (1996) Purification and Properties of Flavin- and Molybdenum-Containing Aldehyde Oxidase from Coleoptiles of Maize. Plant Physiology, 110, 781-789. 
[45] Sekimoto, H., Seo, M., Kawakami, N., Komano, T., Desloire, S., Liotenberg, S., Marion-Poll, A., Caboche, M., Kamiya, Y. and Koshiba, T. (1998) Molecular Cloning and Characterization of Aldehyde Oxidases in Arabidopsis thaliana. Plant and Cell Physiology, 39, 433-442. http://dx.doi.org/10.1093/oxfordjournals.pcp.a029387

[46] Seo, M., Peeters, A.J.M., Koiwai, H., Oritani, T., Marion-Poll, A., Zeevaart, J.A.D., Koornneef, M., Kamiya, Y. and Koshiba, T. (2000) The Arabidopsis Aldehyde Oxidase 3 (AAO3) Gene Product Catalyzes the Final Step in Abscisic Acid Biosynthesis in Leaves. Proceedings of the National Academy of Sciences of the United States of America, 97, 12908-12913. http://dx.doi.org/10.1073/pnas.220426197

[47] Seo, M., Koiwai, H., Akaba, S., Komano, T., Oritani, T., Kamiya, Y. and Koshiba, T. (2000) Abscisic Aldehyde Oxidase in Leaves of Arabidopsis thaliana. The Plant Journal, 23, 481-488. http://dx.doi.org/10.1046/j.1365-313x.2000.00812.x

[48] Bauer, H., Ache, P., Lautner, S., Fromm, J., Hartung, W., Al-Rasheid, K.A., Sonnewald, S., Sonnewald, U., Kneitz, S., Lachmann, N., Mendel, R.R., Bittner, F., Hetherington, A.M. and Hedrich, R. (2013) The Stomatal Response to Reduced Relative Humidity Requires Guard Cell-Autonomous ABA Synthesis. Current Biology, 23, 53-57. http://dx.doi.org/10.1016/j.cub.2012.11.022

[49] Melhorn, V., Matsumi, K., Koiwai, H., Ikegami, K., Okamoto, M., Nambara, E., Bittner, F. and Koshiba, T. (2008) Transient Expression of AtNCED3 and AAO3 Genes in Guard Cells Causes Stomatal Closure in Vicia faba. Journal of Plant Research, 121, 125-131. http://dx.doi.org/10.1007/s10265-007-0127-7

[50] Raab, S., Drechsel, G., Zarepour, M., Hartung, W., Koshiba, T., Bittner, F. and Hoth, S. (2009) Identification of a Novel E3 Ubiquitin Ligase That Is Required for Suppression of Premature Senescence in Arabidopsis. The Plant Journal, 59, 39-51. http://dx.doi.org/10.1111/j.1365-313X.2009.03846.x

[51] Barrero, J.M., Rodriguez, P.L., Quesada, V., Piqueras, P., Ponce, M.R. and Micol, J.L. (2006) Both Abscisic Acid (ABA)-Dependent and ABA-Independent Pathways Govern the Induction of NCED3, AAO3 and ABA1 in Response to Salt Stress. Plant, Cell and Environment, 29, 2000-2008. http://dx.doi.org/10.1111/j.1365-3040.2006.01576.x

[52] Gonzalez-Guzman, M., Abia, D., Salinas, J., Serrano, R. and Rodriguez, P.L. (2004) Two New Alleles of the Abscisic Aldehyde Oxidase 3 Gene Reveal Its Role in Abscisic Acid Biosynthesis in Seeds. Plant Physiology, 135, 325-333. http://dx.doi.org/10.1104/pp.103.036590

[53] Georgopoulou, Z. and Milborrow, B.V. (2012) Initiation of the Synthesis of "Stress" ABA by (+)-[ $\left[{ }^{2} \mathrm{H}_{6}\right]$ ABA Infiltrated into Leaves of Commelina communis. Physiologia Plantarum, 146, 149-159. http://dx.doi.org/10.1111/j.1399-3054.2012.01630.x

[54] Iuchi, S., Kobayashi, M., Taji, T., Naramoto, M., Seki, M., Kato, T., Tabata, S., Kakubari, Y., Yamaguchi-Shinozaki, K. and Shinozaki, K. (2001) Regulation of Drought Tolerance by Gene Manipulation of 9-Cis-Epoxycarotenoid Dioxygenase, a Key Enzyme in Abscisic Acid Biosynthesis in Arabidopsis. The Plant Journal, 27, 325-333. http://dx.doi.org/10.1046/j.1365-313x.2001.01096.x

[55] Qin, X. and Zeevaart, J.A. (2002) Overexpression of a 9-Cis-Epoxycarotenoid Dioxygenase Gene in Nicotiana plumbaginifolia Increases Abscisic Acid and Phaseic Acid Levels and Enhances Drought Tolerance. Plant Physiology, 128, 544-551. http://dx.doi.org/10.1104/pp.010663

[56] Tan, B.C., Joseph, L.M., Deng, W.T., Liu, L., Li, Q.B., Cline, K. and McCarty, D.R. (2003) Molecular Characterization of the Arabidopsis 9-Cis Epoxycarotenoid Dioxygenase Gene Family. The Plant Journal, 35, 44-56. http://dx.doi.org/10.1046/j.1365-313X.2003.01786.x

\section{Abbreviations}

AAO (abscisic-aldehyde oxidase), ABA (abscisic acid), AO (aldehyde oxidase), ABA2 (short-chain dehydrogenase), ABA3 (Moco-sulphurase), GFP (Green fluorescent protein), GUS ( $\beta$-glucuronidase), Moco (molybdenum cofactor), NCED3 (9-cis-epoxycarotenoid dioxygenase), RNAi (RNA-interference), XDH (xanthine dehydrogenase) 


\section{Supporting Information}

Table S1. Primer for cloning and fragment amplification.PtABA3 promoter, AO-RNAi and GFP-ABA3 fragments were amplified directly out of genomic or cDNA. Amplification of the AO promoter was obtained via nested PCR, the ABA3 fragment for the RNAi construct was generated by fusion PCR.

\begin{tabular}{|c|c|}
\hline $\begin{array}{l}\text { Amplified fragments } \\
\text { for poplar transformation }\end{array}$ & Primer \\
\hline \multirow{2}{*}{ PtABA3 promoter } & $\begin{array}{l}\text { Forward: GGG GAC AAG TTT GTA CAA AAA AGC AGG CTT ATA TGC CTC TGT ACA TCG } \\
\text { TGT G }\end{array}$ \\
\hline & Reverse: GGG GAC CAC TTT GTA CAA GAA AGC TGG GTC ATG TTC TTT TTG GCT CTT CTT \\
\hline \multirow{2}{*}{$\begin{array}{l}\text { PtAO2 promoter } \\
\text { outer primer for nested PCR }\end{array}$} & Forward: GGA AGT CAA TTG GCT GTT GAC ATT \\
\hline & Reverse: CTG TGT TTT TTG TGT CTG CGT CAG \\
\hline \multirow{2}{*}{$\begin{array}{l}\text { PtAO2 promoter } \\
\text { inner primer for nested PCR }\end{array}$} & Forward: AAC CCA TCC AAC TTG ATG GCC ACC \\
\hline & Reverse: TTG GAT CCA CAG CGA GCG CAT AAG AAG CTG GC \\
\hline \multirow{2}{*}{$\begin{array}{l}\text { ABA3-RNAi } \\
\text { with intron }\end{array}$} & Forward: TTG GAT CCT CGA GTT CCT GAC ATG TGC TCT ATT AGT \\
\hline & Reverse: TTC CAT GGA ATT CAA TCT GTT GTT GAG GTC GGA CAC \\
\hline \multirow{2}{*}{$\begin{array}{l}\text { ABA3-RNAi } \\
\text { fusion PCR }\end{array}$} & Forward: ACT GAT TTT GAA GAG AAT GAT GTC GAC TTG TGG \\
\hline & Reverse: GAC ATC ATT CTC TTC AAA ATC AGT ATT ACC ATA CC \\
\hline \multirow{2}{*}{ AO-RNAi } & Forward: AAG GAT CCT CGA GTG CCT GTT GTG CAT GAA G \\
\hline & Reverse: AAC CAT GGA ATT CAA GTC AGG GAC AAA GAA AG \\
\hline GFP-ABA3 & $\begin{array}{l}\text { Forward: TTT CTT GGA TCC ATG GAA GCA TTT CTT AAG GAA TTC } \\
\text { Reverse: CAC AAG CGG ATC CTT ATT CAA TAT CTG GAT TAA CTT CTT CCC C }\end{array}$ \\
\hline
\end{tabular}

Table S2. Primer for verification of correct transgene insertion. DNA was isolated from the different $P . \times$ canescenstransformantsPtABA3::GUS, AO- and ABA3-RNAi and GFP-ABA3. Plants containing the different integrated fragments (GUS fusion construct, GFP fusion construct, RNAi cassettes) were used for further experiments.

\begin{tabular}{cl}
\hline \multicolumn{1}{c}{ Inserted foreign DNA } & \multicolumn{1}{c}{ Primer } \\
\hline PtABA3::GUS & Forward: CAA TTG GGT GTT GGT TCT GCC GGG \\
& Reverse: CGG TAA TCA CCA TTC CCG GCG GG \\
& Forward: ACA GTG GTC CCA AAG ATG GAC CCC \\
AO- and ABA3-RNAi cassette & Reverse: GCT GTC GGC TTT CAA AGC TGT ACG \\
& Forward: ACA GTG GTC CCA AAG ATG GAC CCC \\
GFP-ABA3 & Reverse: ATG CCGTTC TTC TGC TTG TCG GCC \\
\hline
\end{tabular}




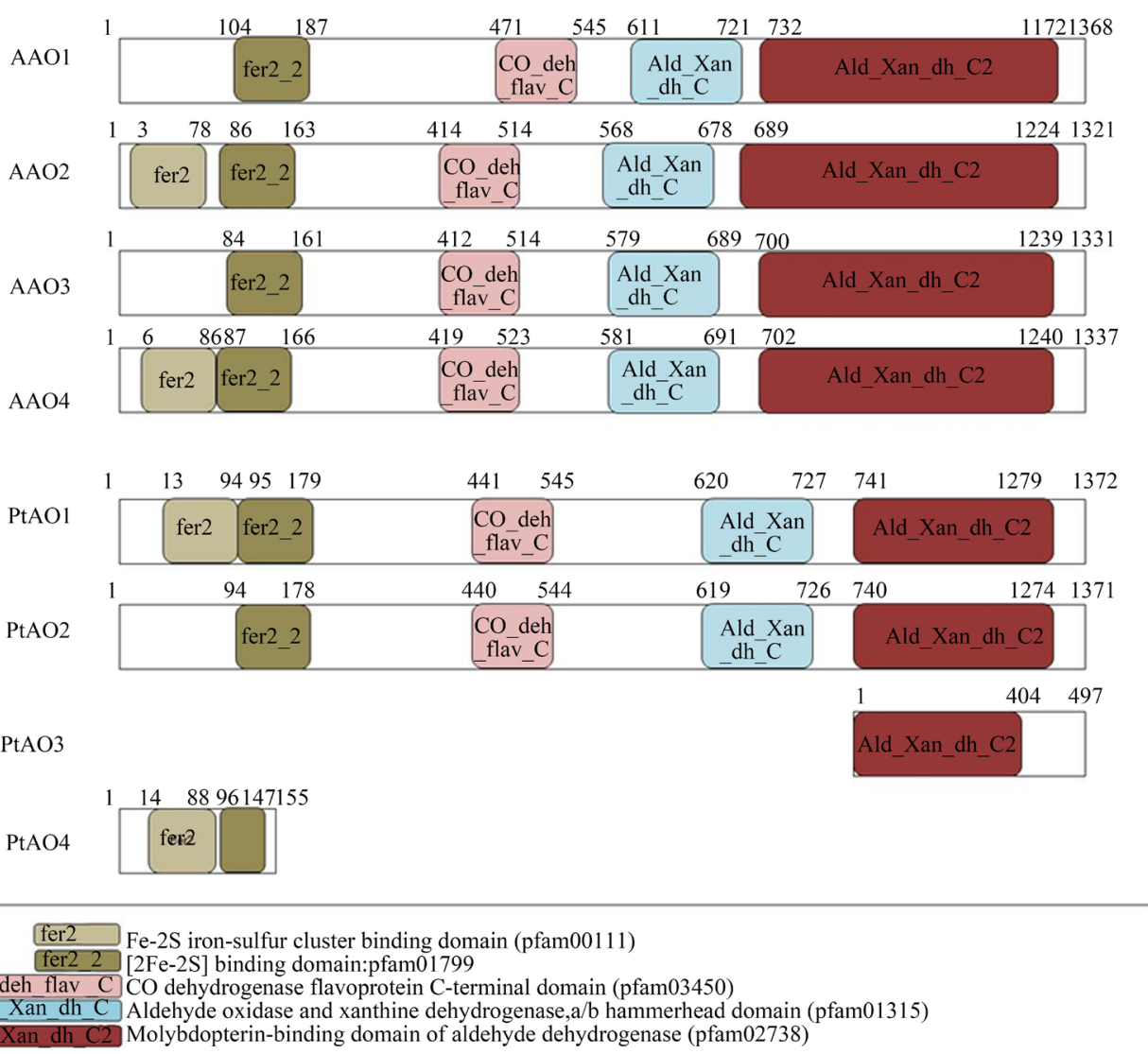

Figure S1. Domain structures of Arabidopsis thaliana aldehyde oxidases (AAOs) and Populustrichocarpa aldehyde oxidases (PtAOs). AAOs are a multigene family with the four isoforms AAO1, AAO2, AAO3 and AAO4. In P. trichocarpa the genes PtAO1, PtAO2, PtAO3 and PtAO4 were identified based on their similarities to Arabidopsis AAO genes. Taking the domain structures into consideration PtAO1 is similar to AAO2 and AAO4 presenting the fer2, the fer2_2, the CO-deh_flav_C, the Ald_Xan_dh_C and the Ald_Xan-dh_C2 domains. PtAO2 and AAO1/AAO3 have high similarities and differ only from the others AO because of the lacking fer2 domain. Both PtAO3 and PtAO4 appear to represent truncated gene copies with either an isolated Ald_Xan_dh_C2 domain or an isolated fer2/ fer2_2 domain. From these, PtAO2 is being the most likely candidate for representing the ABA-synthesizing isoform due its similarity to AAO3.
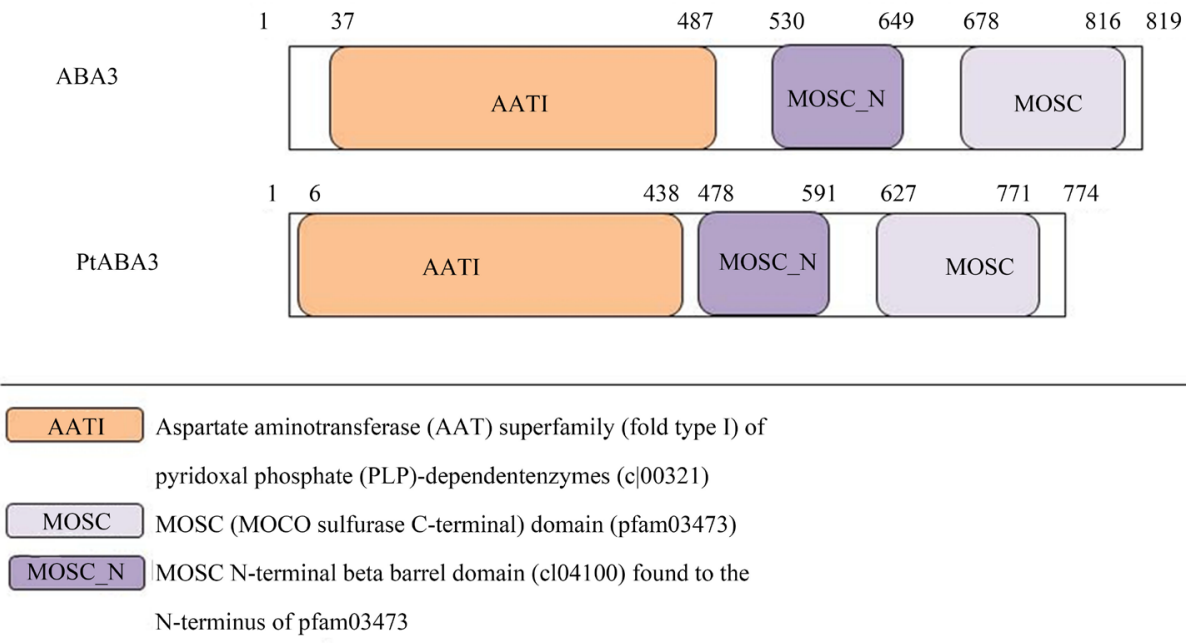

Figure S2. Domain structures of the Mocosulphurase ABA3 in A. thaliana (ABA3) and P.trichocarpa (PtABA3). ABA3 is described in the $P$. trichocarpa database as orthologous to Arabidopsis ABA3 with regard to the domain structures. Both enzymes contain the AATI, the MOSC and the MOSC_N domain. 


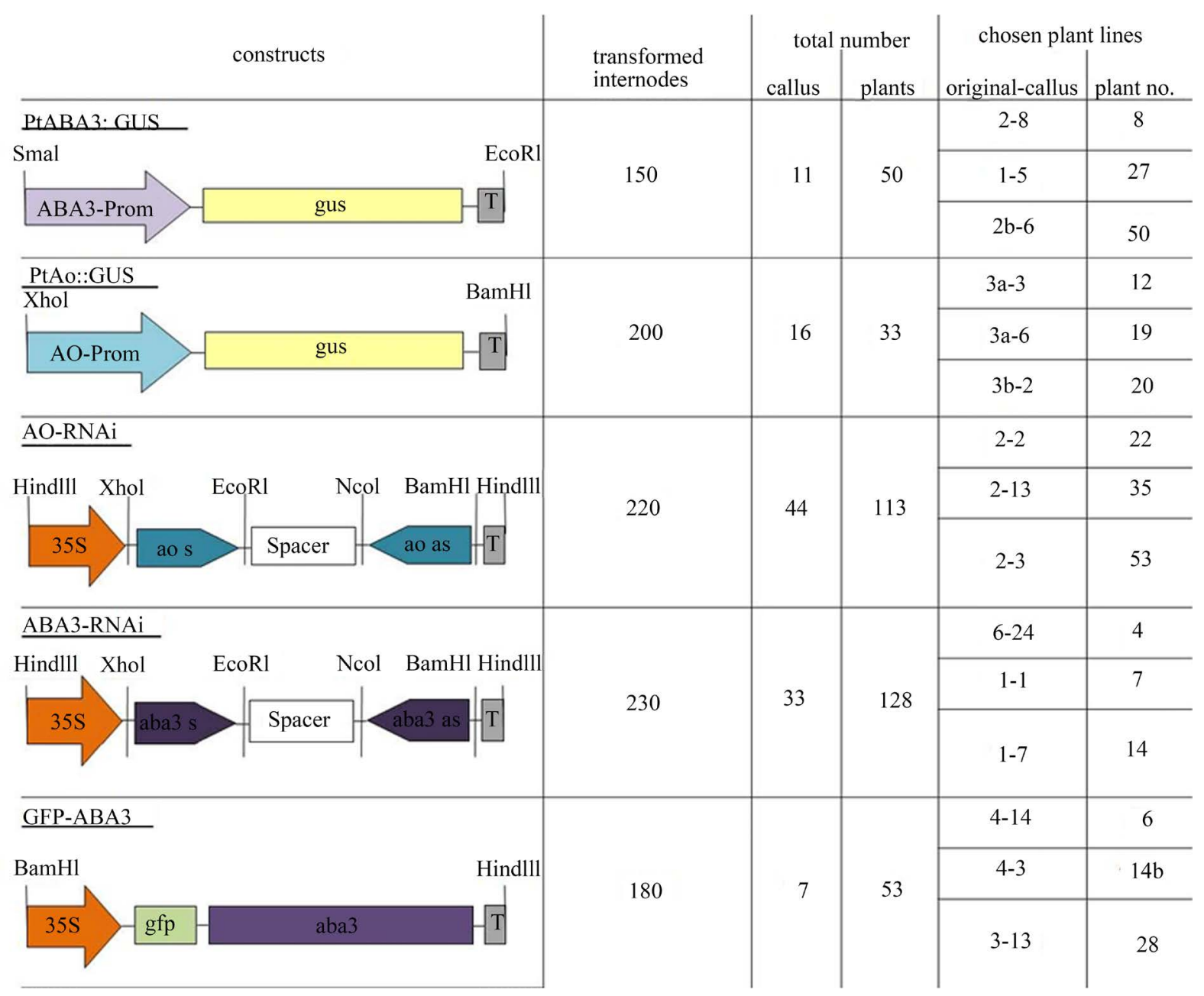

Figure S3. Overview of generated constructs for $P . \times$ canescens transformation. Gene constructs for promoter analyses contained the putative promoter sequences of ptaba3 or ptao 2 which were fused to $\beta$-glucuronidase (gusA). RNAi constructs were generated using the RNAi-cassette obtained from Meyer et al. (2004). ABA3 over-expressors were constructed using a combination of the cauliflower 35S-promoter, the enhanced green fluorescent protein (gusA) and the Arabidopsisaba3 sequence. The ptao2::gusA construct was cloned into the binary vector pKGWSF7 via GATEWAY technology. ptaba3::gusA, $a o-$ and $a b a 3-R N A i$ and $g f p / a b a 3$ were cloned into the pBIN19 binary vector. These constructs were used for stable transformation of $P . \times$ canescens with $R$. tumefaciens using the indicatednumbers of internodes. From several generated calli and callus-derived plants three independently generated plants were chosen for further investigations. Besides the respective genetic modification GUS, AO and XDH activity, microscopically detectable fluorescence and ABA content were criteria for poplar selections. 


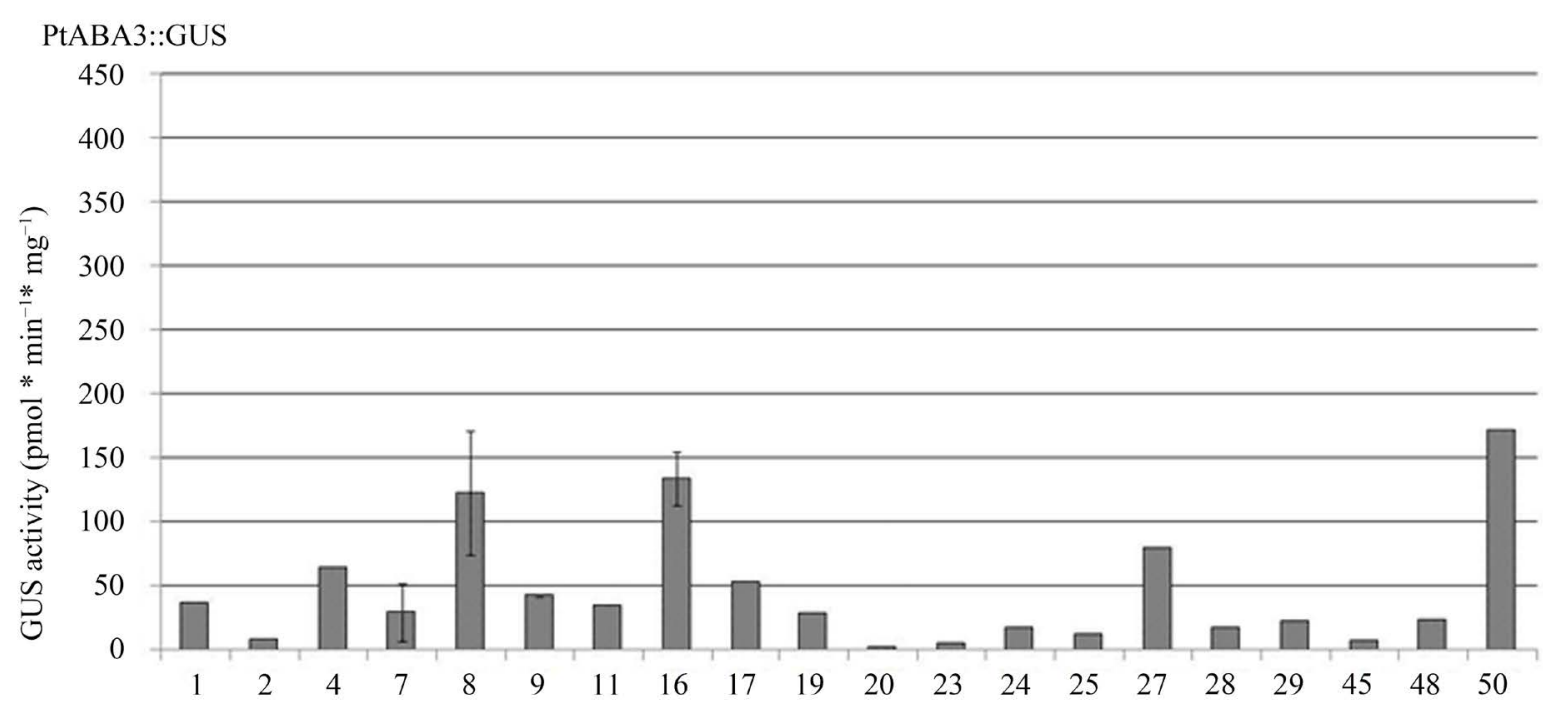

PtAO3::GUS

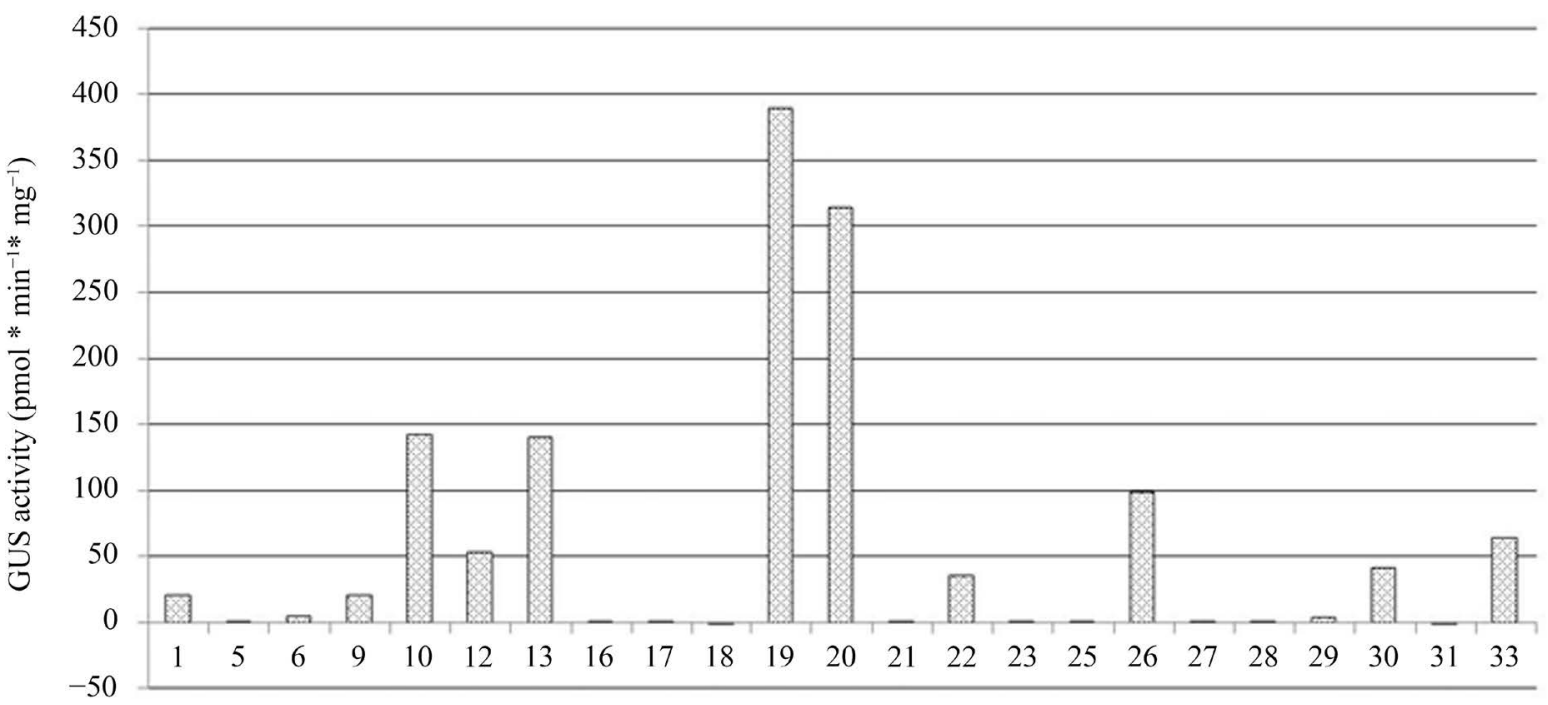

Figure S4. Determination of basal GUS activities for selection of transformed poplar. Constructs were generated using $P$. trichocarpaaba3promotor fused to gusA within the pBIN19 vector and PtAO2 fused to gusA with GATEWAY technologies. The plant selection for further promoter studies was accomplished with regard to basal GUS activities of the different transformants. PtABA3::GUS transformants present a generally lower GUS level than PtAO2::GUS poplar. Plants no. 8, 27 and 50 were chosen for PtABA3::GUS transformants and poplar no. 12, 19 and 20 for PtAO2::GUS according to their appropriate GUS expression. 

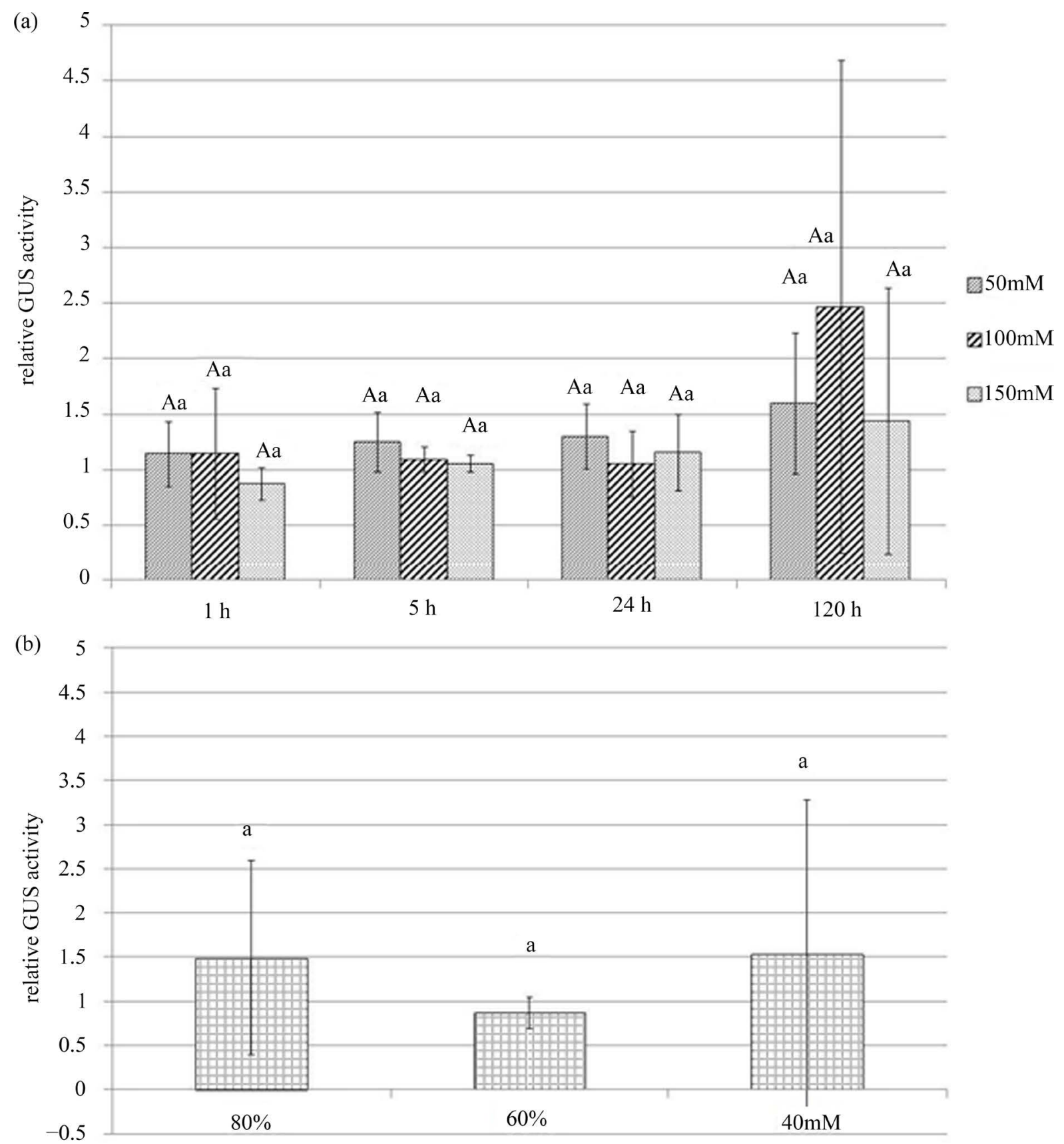

Figure S5. Analyses of variations in aba3-promotor activity during application of high salinity (a) and different drought intensities (b) using PtABA3::GUS transformants and $\beta$-glucuronidase (GUS) measurements. Application of 50, 100 and 150 $\mathrm{mMNaCl}$ for 1, 5, 24 and $120 \mathrm{~h}$ (a) and drying of PtABA3::GUS poplar to 80, 60 and 40\% of their fresh weight (b) is presented. Capital letters indicate significant changes within the experiment based on the duration of salt exposure or alternatively the different drought intensities. Small letters indicate significant differences within the different applicatedNaCl concentrations. Data of PtABA3::GUS transformants no. 8, 27 and 50 were combined. Relative GUS activity was calculated based on the relation of treated salt or drought samples to the referring control samples. 

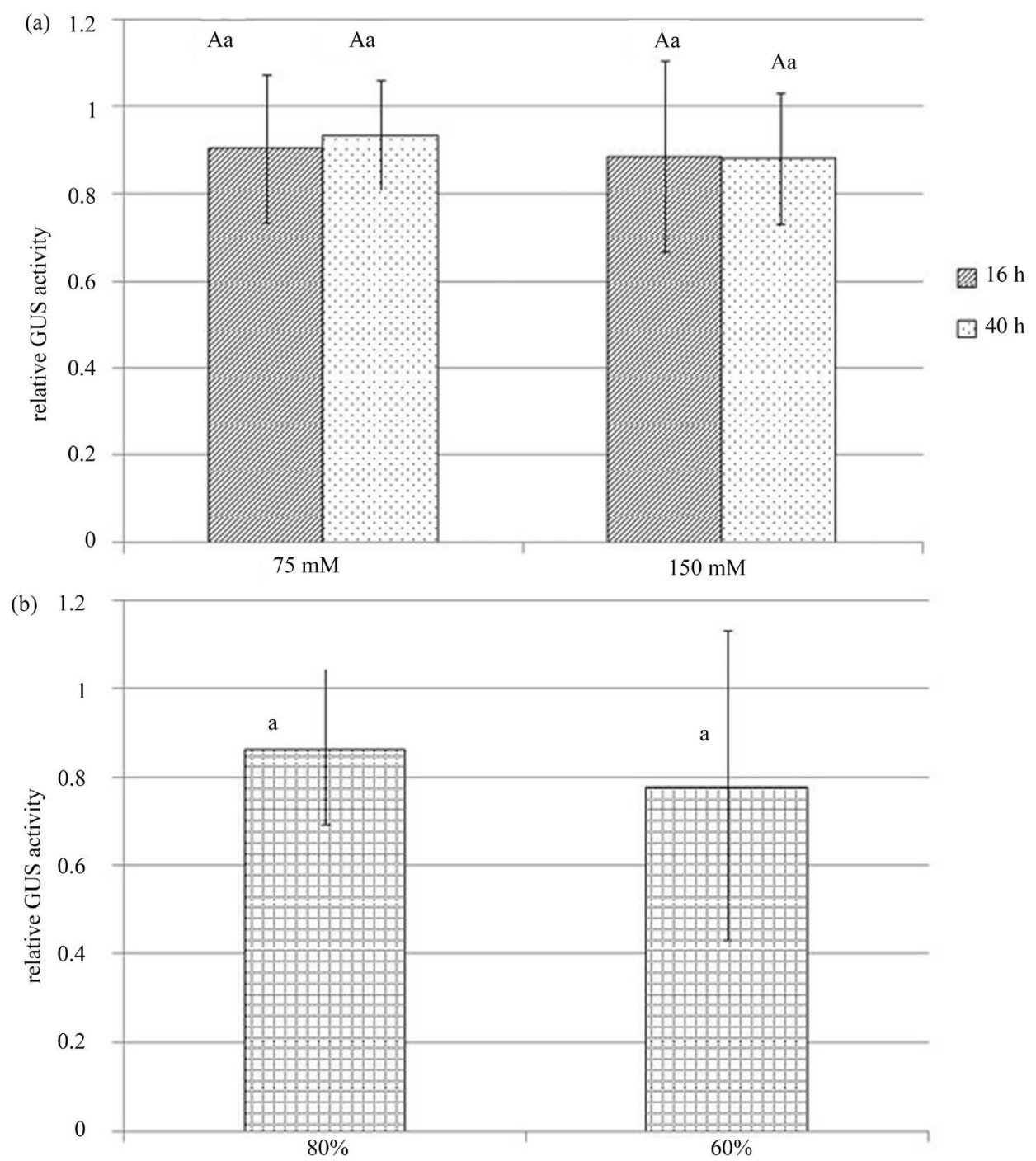

Figure S6. Analyses of variations in PtAO2-promotor activity during application of high salinity (a) and different drought intensities (b) using PtAO2::GUS transformants and $\beta$-glucuronidase (GUS) measurements. Poplar transformed with AO2-promoter constructs fused to gusA were used to investigate changes in AO2 transcription during 16 and $40 \mathrm{~h}$ of exposure to 75 and $150 \mathrm{mMNaCl}$ or during controlled drying to 80 and $60 \%$ of initial leaf fresh weight. Capital letters indicate significant changes of GUS within the used concentration. Small letters indicate differences of GUS levels within the same duration of $\mathrm{NaCl}$ exposure or alternatively between the different drought intensities. GUS data of all investigated poplar lines (no. 12, 19 and 20) were combined and GUS activity was set in relation to GUS activity of control samples for comparability. 


\section{Submit or recommend next manuscript to SCIRP and we will provide best service for you:}

Accepting pre-submission inquiries through Email, Facebook, LinkedIn, Twitter, etc.

A wide selection of journals (inclusive of 9 subjects, more than 200 journals)

Providing 24-hour high-quality service

User-friendly online submission system

Fair and swift peer-review system

Efficient typesetting and proofreading procedure

Display of the result of downloads and visits, as well as the number of cited articles

Maximum dissemination of your research work

Submit your manuscript at: http://papersubmission.scirp.org/ 